\title{
Tsunamigenic earthquake simulations using experimentally derived friction laws
}

\author{
Murphy Shane ${ }^{1,2,{ }^{*}}$, Di Toro G. ${ }^{3,4}$, Romano F. ${ }^{1}$, Scala A ${ }^{1}$, Lorito S. ${ }_{6}^{1}$, Spagnuolo E. ${ }^{1}$, Aretusini S. ${ }^{3}$, \\ Festa G. ${ }^{5}$, Piatanesi A. ${ }^{1}$, Nielsen S. ${ }^{6}$
}

${ }^{1}$ Istituto Nazionale di Geofisica e Vulcanologia, Rome, Italy

${ }^{2}$ Ifremer, Plouzané, France

${ }^{3}$ University of Manchester, Manchester, United Kingdom

${ }^{4}$ Università degli Studi di Padova, Padua, Italy

${ }^{5}$ Università di Napoli Federico II, Naples, Italy

${ }^{6}$ Durham University, Durham, United Kingdom

*Corresponding author : Shane Murphy, email address : shane.murphy@ifremer.fr

\begin{abstract}
:
Seismological, tsunami and geodetic observations have shown that subduction zones are complex systems where the properties of earthquake rupture vary with depth as a result of different pre-stress and frictional conditions. A wealth of earthquakes of different sizes and different source features (e.g. rupture duration) can be generated in subduction zones, including tsunami earthquakes, some of which can produce extreme tsunamigenic events. Here, we offer a geological perspective principally accounting for depth-dependent frictional conditions, while adopting a simplified distribution of on-fault tectonic pre-stress.

We combine a lithology-controlled, depth-dependent experimental friction law with 2D elastodynamic rupture simulations for a Tohoku-like subduction zone cross-section. Subduction zone fault rocks are dominantly incohesive and clay-rich near the surface, transitioning to cohesive and more crystalline at depth. By randomly shifting along fault dip the location of the high shear stress regions ("asperities"), moderate to great thrust earthquakes and tsunami earthquakes are produced that are quite consistent with seismological, geodetic, and tsunami observations. As an effect of depth-dependent friction in our model, slip is confined to the high stress asperity at depth; near the surface rupture is impeded by the rock-clay transition constraining slip to the clay-rich layer. However, when the high stress asperity is located in the clay-to-crystalline rock transition, great thrust earthquakes can be generated similar to the Mw 9 Tohoku (2011) earthquake.
\end{abstract}




\section{Highlights}

- 2D dynamic rupture simulation of earthquakes on the Tohoku fault. Model contains laboratory derived seismic friction laws and subduction geology. Different earthquake types have different depth domains similar to observations. Megathrust events occur when asperity is located in the clay-to-rock transition.

Keywords: subduction zone, megathrust, dynamic rupture, rock physics experiments, tsunami earthquake 


\section{Introduction}

Seismological, geodetic, and tsunami observations have shown that subduction

41 zones are complex systems where the properties of earthquake rupture vary with

42 depth (Lay et al., 2012). For example, earthquake duration normalized for event size

43 has been observed to decrease with depth; this recurrent feature has been attributed to

44 depth varying shear modulus and / or stress drop for individual earthquakes (Bilek

45 and Lay, 1999; Bilek et al., 2016; Geist and Bilek, 2001). Depth variation in

46 subduction ruptures is, for example, evident when comparing the different historical

47 earthquakes that occurred off the Pacific coast of Tohoku region in Japan (Fig. 1). A

48 number of major $\left(M_{w}\right.$ 7-7.9) thrust earthquakes mostly slipped within a depth range of

$4910-40 \mathrm{~km}$. These events involved individual patches of concentrated slip implying 
50 the breaking of at least one prominent, high stress asperity (Shao et al., 2011;

51 Yamanaka and Kikuchi, 2004). Conversely, the 1896 Meiji event (M 8.2 - 8.4), likely

52 involved slip primarily at the base of the shallow accretionary wedge or beneath it.

53 This earthquake produced a disproportionately large tsunami relative to its moment

54 magnitude, possibly making it a potential 'tsunami earthquake' (Kanamori, 1972).

55 The great $\mathrm{M}_{\mathrm{w}} 9.02011$ Tohoku earthquake nucleated at $\sim 20-25 \mathrm{~km}$ depth, and

56 produced slip at traditionally expected depths while also realising a substantial

57 amount of slip all the way to the trench (i.e., at less than $10 \mathrm{~km}$ depth) (Chu et al.,

58 2011; Ide et al., 2011; Romano et al., 2014).

59 Numerical models of the dynamic rupture process have successfully described

60 either individual types of earthquakes, for example the Tohoku event (Kozdon and

61 Dunham, 2013; Noda and Lapusta, 2013), or both thrust and tsunami earthquakes in

62 the same model (Mitsui and Yagi, 2013). Numerical models coupled with the rate-

63 and-state friction law have been used to reproduce full seismic cycles for subduction

64 environments. However, this comes at the expense of either failing to account for

65 geometry / free surface effects and inhomogeneity in the material surrounding the

66 fault (Cubas et al., 2015; Noda and Lapusta, 2013), or by simplifying wave

67 propagation to static stress changes on the fault plane (Shibazaki et al., 2011). Fully

68 dynamic simulations including a free surface and variable geometry have tended to

69 focus on specific rupture features of the Tohoku earthquake such as the slip in the

70 trench or long period guided wave propagation in the ocean (Hirono et al., 2016;

71 Huang et al., 2013; Kozdon and Dunham, 2014). Depth dependent changes in

72 frictional parameters have been tested using rate-and-state models for the 2011

73 Tohoku (Kozdon and Dunham, 2013). However, to our knowledge, no numerical

74 model has been able to reproduce a range of different observed earthquakes types 
75 (e.g. Fig. 1) while at the same time accounting for the fault geometry and complex 76 structure as proposed here.

77 The focus of this study is to provide a simple yet geologically consistent 78 model that reconciles the different observed earthquake types with fault properties 79 from independent theoretical and laboratory studies. We focus our investigation on 80 the aspect of rupture dynamics due to depth-dependent frictional conditions focusing 81 on a specific time window of the seismic cycle including the sub-seismic frictional 82 properties of the fault materials (Den Hartog et al., 2012). Hence, the friction law 83 parameters were chosen based on available geological and geophysical constraints.

84 On the other hand, investigating inter-seismic and nucleation processes is beyond the 85 scope of this study. As a consequence, the set up for the numerical model was 86 simplified, particularly as far as the initial stress distribution is concerned. While the 87 initial stress is heterogeneous, being the derivative of a composite slip model (Murphy 88 et al., 2016), it is highly localized. Moreover, since a 2D model is used, we do not 89 address the influence of lateral variations on rupture features.

90

\section{2. Numerical Model}

92 We modelled the earthquake rupture dynamics (Festa and Vilotte, 2006) on a 2D 93 cross-section through a Tohoku-like fault (Figs. 2a-d). Dynamic rupture is simulated 94 using a 2D non-smooth spectral element method (Festa and Vilotte, 2005). The 95 curved fault geometry is based on Slab 1.0 (Hayes et al., 2012) which has been 96 slightly modified so that the subduction interface extends to the surface. The media is 97 heterogeneous with the layers and their elastic properties (described in Fig. 2 and 98 Table S1 in Supplementary Material) based on a seismic survey in the zone of the 992011 Tohoku earthquake (Miura et al., 2005). 


\subsection{Laboratory derived thermal weakening friction law}

A thermal slip weakening empirical friction law was used in all simulations which is particularly suitable for representing dynamic weakening observed in a regime of slip velocities that rapidly accelerate to seismic slip rates. There are a number of other empirical friction laws (e.g., linear slip weakening (Ida, 1972); rateand-state (Dieterich, 1979; Ruina, 1983)). We have chosen the thermal weakening

107 friction law as it is based on rock physics experiments performed at slip-rates expected during large earthquakes using materials typical in subduction zones.

This law is based on laboratory observations of the evolution of friction with 110 slip in a rotary shear machine where cohesive (serpentinites, peridotites, gabbros, 111 basalts, marbles, granitoids, sandstones, etc.) and non-cohesive (clay-rich gouges, 112 serpentinite gouges, basalt gouges, etc.) rocks were tested over a quite large range of 113 slip rates $(0.1$ to $6.5 \mathrm{~m} / \mathrm{s})$, accelerations $\left(0.5\right.$ to $\left.65 \mathrm{~m} / \mathrm{s}^{2}\right)$, normal stresses (5 to 95 $114 \mathrm{MPa}$ ), ambient conditions (room humidity to fluid saturated) and displacements (0.3 115 to $50 \mathrm{~m}$ ) expected during moderate to large earthquakes (Di Toro et al., 2011). A 116 common feature from this extensive set of experiments is that the evolution of friction 117 with slip can be described by an exponential decay to a first order approximation. 118 This dependency is defined as:

$$
\mu(\delta)=\mu_{d}+\left(\mu_{s}-\mu_{d}\right) e^{\frac{-\delta}{d_{t h}}} \quad(\text { Eq. 1) }
$$

121 where $\mu_{s}$ and $\mu_{d}$ are the static and dynamic friction coefficients, respectively, and 122 depend on material type. The co-seismic slip is $\delta$ and $d_{t h}$ the thermal weakening 123 distance. For a suite of experiments performed at a variety of slip rates and normal 124 stresses, $d_{t h}$ was shown to have an inverse relationship with the normal stress $\sigma_{n}$ : 


$$
d_{t h}=\alpha\left\|\sigma_{n}\right\|^{-\beta} \quad \text { (Eq. 2) }
$$

129 with $\alpha$ ranging between 3 - 78 depending on material type (Di Toro et al., 2011) and $\beta$

$130=1$ (Nielsen et al., 2010). This friction law produces a similar exponential evolution 131 of fault strength with slip to that observed by Hirono et al. (2016) whose numerically 132 modelled thermal pressurization on the Japan Trench using expected permeability and 133 porosity for the region.

\subsection{Variation in fault material}

Depth dependent frictional parameters were chosen based on expected

137 dominant rock types in mega-thrust environments (Hacker et al., 2003a; 2003b;

138 Kimura et al., 2012; Meneghini et al., 2010). Initially unconsolidated and, in the case 139 of Tohoku, clay-rich sediments (Chester et al., 2013), undergo compaction, 140 dehydration, diagenesis and metamorphism into crystalline rocks (phyllites, schists, 141 calc-schists, marbles, quartzites, etc.) due to increasing pressure and temperature 142 during burial (Hacker et al., 2003b; 2003a; Hyndman et al., 1997; Ikari et al., 2007; 143 Kimura et al., 2012). Consequently, high velocity experiments on peridotite (Del 144 Gaudio et al., 2009) were taken as a proxy for mantle rock (i.e., $\mu_{s}=0.7, \mu_{d}=0.25, \alpha$ $145=78$ ), however gabbro, basalts and serpentinite have similar frictional properties 146 when sheared under seismic deformation conditions (Niemeijer et al., 2011; Proctor et 147 al., 2014; Violay et al., 2014). For clay-like material the static and dynamic 148 coefficients of friction were set to 0.25 and 0.1 respectively based on experiments 149 performed under room humidity conditions and in the presence of liquid water 
150 (Remitti et al., 2015; Sawai et al., 2014; Ujiie et al., 2013). Experimental studies from

151 literature were used to determine the $\alpha$ value used for the clay-like material in the 152 numerical model (see Fig 3 and Table S3 in Supplementary Material). Most of the 153 latter experiments were performed at room humidity on a variety of different clay 154 minerals and under increasing normal stresses. Ideally, data from experiments on 155 unconsolidated wet clay materials would be used. However, experiments at high 156 normal stress $(>20 \mathrm{MPa})$ are very challenging on these materials and not enough data 157 exist to calculate the variation of $d_{t h}$ with normal stress. Setting $\beta=1$ based on 158 theoretical findings (Nielsen et al., 2010), $\alpha=3.712$ provided the best fit for 159 equation 2 to the experimental data (see Fig. 3) with a R-square of 0.735 and a $95 \%$ 160 confidence bounds of 3.32 to 4.11 . Below $40 \mathrm{~km} d_{t \mathrm{~h}}$ was artificially increased to $20 \mathrm{~m}$ 161 in order to act as a numerical barrier to rupture at the bottom of the fault. This depth 162 was chosen as it corresponds to the depth at which co-seismic slip in the $2011 \mathrm{M}_{\mathrm{w}} 9.0$ 163 Tohoku earthquake rapidly decreased and the largest post-seismic slip occurred 164 (Ozawa et al., 2011). This is also the estimated depth where creep begins (Freed, 165 2005).

166 Using an effective basal friction of 0.03 , thermal modelling of the Tohoku 167 fault (Kimura et al., 2012) places the $50^{\circ} \mathrm{C}$ isotherm at $10 \mathrm{~km}$ depth and $150^{\circ} \mathrm{C}$ 168 isotherm at a depth of $20 \mathrm{~km}$. Guided by these findings, we defined the frictional 169 parameters above $2 \mathrm{~km}$ as clay-like, with a linear transition to rock-like frictional 170 parameters in the $12-20 \mathrm{~km}$ depth range. This interval accounts for peak dehydration 171 due to opal to quartz and smectite to illite conversion rates estimated to occur at 12 $172 \mathrm{~km}$ depth (Kimura et al., 2012). This transformation is consistent with experimental 173 findings on clays that showed only a minor increase in the coefficient of friction as a 174 function of smectite-to-illite transformation and effective normal stress (i.e. from 0.27 

coefficient associated with a decrease in water content (e.g. by dehydration), or an increase in quartz content in the system (e.g. by silicization and/or precipitation of quartz veins) (Ikari et al., 2007).

\subsection{Bi-material fault surface}

The subduction interface is on the boundary between the oceanic lithospheric layer and various hanging-wall materials (e.g., wedge and various mantle layers that vary with depth) which can lead to ill-posedness and numerical instability in terms of modelling due to the bi-material propagation (Cochard and Madariaga, 1996). To accommodate for this, the evolution of the normal stress is regularized whereby the frictional strength depends on the evolving normal stress $\sigma_{\mathrm{e}}$ that, in turn, varies due to normal stress perturbations $\sigma_{\mathrm{n}}$ depending on either a slip-rate-based or a constant characteristic time scale (Rubin and Ampuero, 2007):

$$
\frac{d \sigma_{e}}{d t}=\frac{\alpha_{e}|v|+v^{*}}{\delta_{D}}\left(\sigma_{n}-\sigma_{e}\right)
$$

where $v^{*}$ is a characteristic slip rate, $\delta_{\mathrm{D}}$ a characteristic slip scale, $|v|$ is the local value

194 of slip rate, and $\alpha_{\mathrm{e}}$ can assume the values 0 or 1 . For this study, $v^{*}=0, \alpha_{e}=1$, and $\delta_{D}=0.3 d_{t h}$ were used as they were found to produce numerically stable and 196 physically convergent solutions (Scala et al., 2017). The relationship between the 197 classical slip weakening distance, $d_{c}$ and the thermal weakening distance, $d_{t h}$, is $d_{c} \approx 3 d_{t h}$ (Di Toro et al., 2011). 
In order to account for the effect of fluids we consider the dynamic Coulomb wedge theory (Wang and $\mathrm{Hu}, 2006$ ) which proposes that fluid pressure ratio, $\lambda$, and effective basal friction, defined as $\mu_{b}^{\prime}=\mu(1-\lambda)$ (Wang et al., 2010) where $\mu$ is the 204 coefficient of friction, vary between the front, middle and back of the forearc prism. 205 Based on analysis of seismic profiles and thermal models (Kimura et al., 2012), $\lambda=$ 2060.9 was applied to the section of the fault at the back of the prism with $\lambda=0.95$ (depth $207>14.6 \mathrm{~km}$ ) for the middle section of the prism (depth range of $9.6-14.6 \mathrm{~km}$ ). For the 208 frontal section of the prism $(<9.6 \mathrm{~km}), \lambda=0.65$ was used. Assuming that $\mu$ is similar 209 to the static friction coefficient used in our dynamic simulations (i.e., $\mu=\mu_{s}$ ) we can 210 compare our initial conditions with other studies. The initial conditions for our 211 numerical model exhibits $\mu_{b}^{\prime}$ of $0.0875,0.0125$ and 0.025 to 0.07 for the front, middle 212 and back sections of the accretionary wedge which is comparable to observations (i.e., $213>0.08,<0.03$ and 0.03 for the respective sections of the prism) (Kimura et al., 2012) 214 and $\mu_{b}^{\prime}=0.025$ for the whole fault (Gao and Wang, 2014). Using this depth 215 dependent $\lambda$, the principal vertical component of stress was estimated as the 216 difference between lithostatic normal load and hydrostatic pore pressure using the 217 principal vertical stress $\sigma_{3}=(1-\lambda) g \rho z$, where $g$ is the gravity, $\rho$ is the density and $218 z$ is the depth. The fluid retention depth, $Z_{\mathrm{FRD}}$, is the point at which fluid pressure 219 increases at the same rate as the lithostatic gradient (Suppe, 2014). It defines the 220 strength of the fault at depth: the deeper $Z_{\mathrm{FRD}}$ is, the stronger the fault becomes, and if 221 all other parameters are similar, the larger the potential stress drop could be during 222 rupture below $Z_{\mathrm{FRD}}$. We assumed $\mathrm{Z}_{\mathrm{FRD}} \sim 12 \mathrm{~km}$, the point at which the transformation 223 of the frictional parameters from clay-like to rock-like has ended. Therefore, $\sigma_{3}$ tracks 224 the lithostatic gradient below $\mathrm{Z}_{\mathrm{FRD}}$. The horizontal principal stress, $\sigma_{1}$, was set to 4.05 
$\sigma_{3}$ (see Section A2 in Supplementary Material on discussion on choice for this scaling

226 factor). The effective normal stress on the fault is calculated based on fault geometry

227 relative to the two principal components of stress. The fault strength, that is the stress

228 at which the fault fails, is a function of the static friction coefficient and the effective

229 initial normal stress (black dashed line in Fig. 4a).

230

\subsection{Initial shear stress distribution}

As discussed in the introduction, many of the historical thrust earthquakes in

233 the Tohoku region (Fig. 1), can be described with one patch of heterogeneous but 234 concentrated significant slip suggesting that only one major high shear stress 235 "asperity" might have failed at the yield stress in these events. While this may not be 236 always the case, as earthquakes exhibit in general a large variability in the complexity 237 of their slip distributions (e.g. Lorito et al., 2016), a simplified single high stress 238 asperity model is used here, where the initial stress is spatially concentrated in 239 different locations along the fault plane. In reality, the initial shear stress on the fault 240 plane varies both spatially and temporally and is dependent on a number of 241 phenomena such as loading rate, coupling, and historical earthquakes (Nalbant et al., 242 2013).

243 In order to control the location of the high stress asperity, the initial shear 244 stress distribution was generated by taking the spatial derivative of a $1 \mathrm{D}$ 245 heterogeneous slip distribution constructed using a composite source model (Murphy 246 et al., 2016). The location of the high stress asperity is placed randomly on the fault 247 plane for each simulation. The maximum allowable shear stress in the model is 248 defined by the fault strength, meaning that asperities in the crystalline rock material 249 contain higher stress compared with asperities in clay-like material. Nucleation is 
achieved by lowering the effective normal stress such that the fault strength is a few

251 percent below the initial shear stress (see Fig. S2 in Supplementary Material for 252 examples). The location of the nucleation is randomly chosen to be within the asperity 253 on the fault.

3. Results

Initially, three separate simulations with asperity locations at different depths were chosen $(15 \mathrm{~km}, 19 \mathrm{~km}$ and $36 \mathrm{~km})$ as a case study (Fig. 4a). These three simulations are referred to as "shallow" (blue), "intermediate" (orange) and "deep" (purple) in reference to the relative location of the three asperities. Later this procedure is extended to 45 simulations with asperity locations randomly chosen between $10-40 \mathrm{~km}$ depth.

\subsection{Breakdown Energy}

The three simulations produce radically different slip distributions (Fig. 4b):

264 the deep asperity produced a concentrated patch of slip (maximum slip of $16 \mathrm{~m}$ ); the 265 intermediate asperity produced the largest earthquake (maximum slip of $38 \mathrm{~m}$ ) with 266 surface rupture; while the shallow asperity produced the smallest earthquake

267 (maximum slip of $9.5 \mathrm{~m}$ ). The differences in the amount of slip and earthquake size in 268 our model can be traced back to the depth variation of the fault strength (Fig. 4a) and 269 its evolution with slip (Fig. 4c). This depth dependence in turn plays an important role 270 in controlling the interplay between the release of stored elastic energy and

271 breakdown energy, $G_{b}^{i}$. The breakdown energy $G_{b}^{i}$ has been calculated by numerically 272 integrating the evolution of shear stress over the slipping distance using the formula 273 (Abercrombie and Rice, 2005):

$$
G_{b}^{i}=\int_{0}^{\delta}\left[\tau\left(\delta^{\prime}\right)-\tau(\delta)\right] d \delta^{\prime} \quad(\mathrm{Eq} .4)
$$


277 where $\delta$ is the total slip. The $G_{b}^{i}$ was calculated of each point on the fault where co278 seismic slip occurs in the three case studies depicted in Fig 4. The amount of energy 279 required to propagate the rupture dramatically increased below $17 \mathrm{~km}$ depth by at 280 least a factor of 50 as shown in Fig. 5a.

\subsection{Energy Release Rate}

The stress drop, $\Delta \sigma$, systematically increased from $4 \mathrm{MPa}$ to $20 \mathrm{MPa}$ with increasing depth (Fig. 5b). The static stress drop has been calculated using $\Delta \sigma=\tau_{o}-$

$\tau_{f}$ where $\tau_{f}$ is the shear stress at the end of rupture and $\tau_{o}$ is the initial shear stress (Kato, 2012). Negative stress drop may occur (as is the case in Fig. 5b) when the stress at a point on the fault is higher at the end of the simulation than at the start. This can occur beyond the arrest region of the earthquake where fault strength does not evolve to residual dynamic strength and therefore the stress in this zone is at a higher

290 level relative to before the earthquake. Negative stress drops may also occur when the 291 initial stress is less than the dynamic strength of the fault $\left(\tau_{o}<\mu_{d} \sigma_{n}\right)$, in such cases rupture can continue to propagate in these unfavourable zones for a limited distance

293 depending on the energy release rate and $G_{b}^{i}$ (Kozdon and Dunham, 2013).

294 Taking the square of the static stress drop as a proxy for the energy release 295 rate $\left(G^{*} \propto \Delta \sigma^{2}\right.$, assuming rupture velocity remains constant (Nielsen et al., 2016)), 296 this latter quantity increased by a factor of 25 with depth. This depth-dependent 297 relative difference between $G_{b}^{i}$ and $G^{*}$ made it difficult for rupture to propagate out of 298 the trench zone. Therefore, earthquakes that nucleate in shallower clay-rich lithology 299 are more likely to propagate along strike rather than down-dip producing the large 
length-to-width ratios observed for tsunami earthquakes (e.g., 1896 Meiji (Tanioka and Satake, 1996), 1992 Nicaragua (Ihmlé, 1996), 2006 Java (Ammon et al., 2006)).

\section{3 "Shallow" earthquakes}

Comparing the deepest and shallowest nucleating earthquakes in Fig. 4a, both have comparable duration (Fig. 6a) and tsunami source amplitude (Fig. 6b and Section A3 in Supplementary Material) despite the latter being smaller in size; these findings make the shallowest event in principle compatible with a tsunami earthquake (Grezio et. al., 2017; Satake and Tanioka, 1999). Additional simulations reveal that

309 earthquakes with centroid depth (i.e., the average depth of the slipping area of the earthquake weighted by the slip) located in the high pore pressure zone under the accretionary wedge had consistently longer normalized rupture durations (duration of earthquake has been normalized with respect to moment, see Section A4 in

313 Supplementary Material) when compared with earthquakes from other zones on the

314 fault (Fig. 7a). This is a systematic feature in our simulations and it is also consistent 315 with seismological observations (Bilek and Lay, 1999). This depth dependent 316 variation of rupture duration is due to a decrease in both the average stress drop and 317 rigidity (Figs. 7b-c) at shallow depths confirming the hypothesis that rupture duration 318 is linked with depth varying mechanical properties (Bilek and Lay, 1999). 319 Additionally, for earthquakes where significant slip is in the high pore pressure zone 320 the average rupture velocities were in the range of $1.2-2.2 \mathrm{~km} / \mathrm{s}$ (Fig. 7d). This range 321 is comparable to that estimated for tsunami earthquakes (e.g., 2006 Java $M_{w} 7.8$ 322 tsunami earthquake which occurred close the Sunda trench and had a rupture velocity 323 range of $1.0-1.5 \mathrm{~km} / \mathrm{s}$ (Ammon et al., 2006)). Hence, the shallow earthquake (blue 324 line in Fig. 4b), with its longer duration, small average stress drop and slow average 
rupture velocity, appears to be similar to the 1896 Meiji tsunami earthquake (Tanioka and Satake, 1996) (Fig. 1).

\section{4 "Intermediate" depth earthquake}

For the intermediate earthquake (orange line and dots, Figs 4-6), nucleation was in a zone where $G^{*}$ and $G_{b}^{i}$ are large (end of the rock to clay transition), but as

rupture propagated up-dip the fault became weaker and $G_{b}^{i}$ became smaller in the clay-rich material. Additionally, in thrust environments, seismic waves generated at depth by rupture and reflected back onto the fault by the free surface have been shown to induce tensile normal stress perturbations producing larger stress drops and slip near the surface (Nielsen, 1998; Oglesby et al., 1998) as well as promoting rupture in 336 shallow velocity-strengthening environments (Kozdon and Dunham, 2013). This has 337 also been noted in laboratory experiments where velocity strengthening clays at slow 338 slip-rates and low effective normal stresses $(<30 \mathrm{MPa})$ become velocity weakening 339 (Saffer and Marone, 2003) and have at the same time low $G_{b}^{i}$ at slip-rates comparable 340 to those observed during earthquakes (Faulkner et al., 2011). This means that rupture 341 can easily propagate into clay-rich zones even when there is little initial shear stress present in the accretionary wedge.

343 This easier rupture propagation in clay-rich zones could explain the large size 344 of 2011 Tohoku earthquake which nucleated at $20-25 \mathrm{~km}$ depth (Chu et al., 2011).

345 In the case study, rupture travelled up-dip into the wedge, with a significant amount of 346 slip occurring above $15 \mathrm{~km}$ depth, which is comparable to the slip inversions for the 347 Tohoku earthquake (e.g. Romano et al., 2014, Fig. 1). The seismic moment release 348 rate from the intermediate asperity is much larger and longer than the deepest and 349 shallowest earthquakes (Fig. 6a) and produced the largest tsunami source (Fig. 6b). In 
some simulations where the asperity is located at a slightly deeper depth than the

351 intermediate case study, rupture that initially propagates up-dip to the surface then

352 propagated back down the fault again (Fig. 8c), this is a feature that has been

353 suggested for the $2011 \mathrm{M}_{\mathrm{w}} 9$ earthquake (Ide et al., 2011). Hence, we classify the

354 intermediate simulation as a great thrust earthquake similar to the $2011 \mathrm{M}_{\mathrm{w}} 9.0$

355 Tohoku earthquake.

\section{5 "Deep" earthquakes}

For the deep earthquakes, the distance between the asperity and the clay-rich trench is relevant. This is shown in Fig. 7e, where the earthquakes with the largest seismic moment release had centroid depths between $15-20 \mathrm{~km}$. Below a certain depth of $\sim 26 \mathrm{~km}$, the distance from asperity to the clay-rich material was too far relative to the $G^{*}$ for rupture to reach it; this produced a relatively smaller thrust earthquake (e.g., the 'deep' case study, purple line and dots, in Figs 4-6). These

364 smaller thrust earthquakes had centroid depths below $20 \mathrm{~km}$, had a larger stress drop 365 (Fig. 7b), a faster rupture velocity (Fig. 7d) and larger average $G_{b}^{i}$ (Fig. 7f) compared 366 to the great thrust and tsunami earthquakes. They produced only one patch of 367 significant slip making them comparable to the historical $\mathrm{M}_{\mathrm{w}} 7-8$ thrust earthquakes 368 in Fig. 1.

\section{Discussion}

\subsection{Varying scaling between principal stresses}

373 Several assumptions were made in the construction of the numerical model. 374 Therefore, a sensitivity study was performed to determine the robustness of the 
variation with depth of seismic ruptures features, in response to the initial parameters chosen in the model. For example, in the original set of simulations, the principal components of stress were assumed to have a $\sigma_{1}=4.05 \sigma_{3}$. In an additional set of 15 simulations, this was changed to $\sigma_{1}=5.0 \sigma_{3}$ to evaluate the effect of different regional principal stresses ratios. The value $\sigma_{1}=5.0 \sigma_{3}$ was selected based on previous studies which used ratios of 4.7545 (Ma, 2012) and 5.0 (Brace and

381 Kohlstedt, 1980). Comparing the average moment release, stress drop, $G_{b}^{i}$ and rupture 382 velocity per simulation (Fig. S8 in Supplementary Material), the change in principal 383 stress ratios has not affected the depth dependent features observed in the original set 384 of simulations.

\subsection{Varying the fluid retention depth}

Another test was done to examine the effect of altering the fluid retention depth, $Z_{\mathrm{FRD}}$. Two additional sets of simulations (15 in each case) were run where $\mathrm{Z}_{\mathrm{FRD}}$ was shifted $\pm 5 \mathrm{~km}$ from the original depth, i.e. $7 \mathrm{~km}$ and $17 \mathrm{~km}$. The effect on yield stress and initial stress distributions, can be viewed in the Supplementary Material

391 (i.e. Fig. $S 4$ for the original setup, Fig. $S 6$ for $Z_{\mathrm{FRD}}=7 \mathrm{~km}$, and Fig. $\mathrm{S} 7$ for $\mathrm{Z}_{\mathrm{FRD}}=17$ $392 \mathrm{~km}$ in Section A5). Fig. 9 shows that the earthquakes in the ensemble with $Z_{\mathrm{FRD}}=17$ $393 \mathrm{~km}$ produce more energetic earthquakes (i.e. large moment release and stress drop for 394 intermediate size events). However, the general depth dependent trend observed in 395 the original set of simulations (i.e., $Z_{\mathrm{FRD}}=12 \mathrm{~km}$ ) is still present. This is not the case 396 when $Z_{\mathrm{FRD}}=7 \mathrm{~km}$ where the depth dependent trends observed in the original study 397 break down with earthquakes at depth exhibiting low rupture velocities $(\approx 1 \mathrm{~km} / \mathrm{s})$ and 398 long normalised duration. This breakdown in trend is due to the deeper sections of the 399 fault becoming too weak (the yield stress drops below $20 \mathrm{MPa}$ ) to store sufficient 
elastic strain energy relative to the breakdown energy. For $Z_{\mathrm{FRD}}=7 \mathrm{~km}$ there is still

401 an increase in earthquake moment release at the transition from rock to clay-like 402 material (between 10 - $20 \mathrm{~km}$ depth, Fig. 9a) albeit over a reduced scale both in terms 403 of variation in moment and the spatial extent. Therefore, the effect of the rock-clay 404 transition is still present, but as the strength of the deeper section of the fault has 405 become comparable to the near-surface conditions this leads to a breakdown in the original depth-dependent trend.

\subsection{Initial stress distributions}

While the initial stress distributions used in these simulations were based on a

410 single broad asperity model, in nature, the actual distribution is possibly more

411 complex, and generally unknown. By lowering the initial stress below the residual

412 shear stress outside of the asperity (i.e., $\tau<\mu_{d} \sigma_{n}$ ) rupture propagation was curtailed.

413 Repeating the case studies presented in Fig. 4 with a higher initial stress outside of the 414 asperity (i.e., $\tau=\mu_{d} \sigma_{n}$ ) produced similar slip distributions for the shallowest and 415 deepest earthquakes (see Fig. 10). The intermediate depth earthquake was larger (with $416>50 \mathrm{~m}$ slip) in comparison with the original simulation. This is due to the intermediate 417 earthquake nucleating near the strongest section of the fault which acts as a barrier in 418 the other two cases. To continue to increase the initial shear stress outside of the 419 asperity would ultimately lead to all earthquakes rupturing the full seismogenic zone 420 with very little constraint on nucleation location and/or initial asperity location.

421 Whether sections of the fault contain shear stress lower than the residual shear 422 strength is unknown; phenomena such as dynamic overshoot and low coupling may 423 contribute to it occurring. Alternative phenomena that would cause rupture arrest 424 include increasing fault strength or $G_{b}^{i}$ due to change in effective normal stress (i.e., 
due to changes in pore pressure/fault geometry) and/or frictional parameters (i.e., variations in fault material types). Our simplification provided a method for

427 decoupling rupture features at different depths, and despite its limitations revealed

428 itself effective in clarifying significant general relations between frictional properties 429 and rupture dynamics in a subduction environment.

A less simplistic initial stress distributions could be achieved, for example, by 431 considering multiple asperities of varying sizes on the fault plane. In such a situation 432 rupture becomes more complex, for example rupture velocity and slip-rate have been 433 shown to be strongly affected by sharp changes in initial shear stress and frictional 434 parameters on the fault plane (Huang et al., 2013). In the simulations presented in this 435 study, rupture velocity generally varies smoothly (see Fig. 8) with the exception being 436 in certain cases when the asperity is located at intermediate depths where the rupture 437 jumps to the very high pore pressure zone (Fig. 8c) due to this section of the fault 438 being very weak. This effect could be negated by considering a highly compliant 439 wedge or off-fault inelastic deformation (as the current numerical model is purely 440 elastic), particularly around the high pore pressure zone, which would slow down the 441 rupture velocity (Lotto et al., 2017; Ma, 2012).

442 Finally, our pre-stress models are not derived from a complete description of a 443 seismic cycle on the analysed fault, since our goal was to understand how depth444 dependent frictional behavior may control, to first order, rupture dynamics.

\subsection{Along strike variation of frictional parameters}

The numerical models presented here are two dimensional and do not account

448 for along strike heterogeneity (i.e. the fault is a line rather than a 2D surface). For 449 example, strong variations in the fluid retention depth along the strike of the fault 
would lead to along strike variation in fault strength at depth. In our simulations,

451 moving the fluid retention depth up $7 \mathrm{~km}$ weakened the fault at depth with the result

452 that great earthquakes were no longer generated at depth (compare blue and black

453 dots in Fig. 9). As demonstrated by the smaller size of earthquakes that nucleated at

454 shallow depths in our ensemble of simulations, it is difficult for rupture to propagate 455 into stronger patches of the fault. Shao et al. (2011) proposed that the repeat M7 456 earthquakes (i.e., 1981 and 2011) occur in relatively weak sections of the fault 457 compared to a potential stronger patch where the 2011 M9 earthquake nucleated. This 458 hypothesis is complementary to our findings whereby along strike variations in the 459 fluid retention depth provides one possible mechanism to explain variations in 460 strength. Other mechanisms such local changes in fault material, fault geometry and 461 pore pressure are other potential means of causing along strike variations in fault 462 strength. On a two-dimensional surface this additional complexity in turn makes 463 rupture propagation more complex as it can conceivably go around barriers while the 464 relative location of surrounding high stress asperities to nucleation can produce 465 rupture directivity (Murphy and Nielsen, 2009). Consequently, while our 2D dynamic 466 model produces depth dependent features similar to seismological observations (Bilek 467 and Lay, 1999), further work involving 3D dynamic rupture simulations would be 468 required to investigate the role of along strike heterogeneity. Particularly in explaining 469 the difference between M7 earthquakes relative to the M9 2011 earthquake given that 470 they nucleate at similar depths.

\subsection{Friction Law}

With the choice of slip weakening friction law, earthquake rupture was

474 generally crack-like in the simulations (Fig. 8). Friction laws where fault strength 
evolves with slip rate are more likely to produce pulse-like ruptures (Nielsen and

476 Carlson, 2000; Zheng and Rice, 1998), with shorter rise-time compared to crack-like 477 ruptures. Additionally, velocity-strengthening zones near the surface can further 478 complicate rupture dynamics (Kozdon and Dunham, 2013; Lotto et al., 2017). 479 Consequently, it would be beneficial to perform studies with rate-based friction laws 480 in the future.

Ultimately, the aim is to simulate the full seismic cycle with friction laws

482 derived from experiments (and physical fault processes) that are consistent with 483 conditions on the fault during the different stages of the seismic cycle. Nevertheless, 484 despite the simplified framework provided by the single asperity model used here, our 485 model manages to reproduce observed geophysical features between the different 486 subduction zone earthquake types in this mega-thrust environment. The observed 487 differences, can, to first order, be ascribed to rupture dynamics effects coupled with a 488 depth-dependent friction law based that accounts for the expected geology at the 489 Japan Trench.

\subsection{Site specific nature of study}

Our findings are regional as they are specific to the Tohoku trench environment. A meaningful extrapolation of these results to other subduction zones

494 would require at least similarity in depth dependent frictional properties and fault 495 geometry. For example, in this study, frictional properties based on a clay-like material was chosen as this was observed at Tohoku (Chester et al., 2013). However,

497 soft sediment in the nearby Nankai trench is more sandy in nature (Hirono et al., 498 2014). Dynamic simulations comparing the two environments have shown that a more 499 sandy sediment produces a larger thermal pressurisation during dynamic rupture but 
this is offset by higher initial excess fluid pressure (Hirono et al., 2016).

501 Consequently, care must be taken in applying the finds from one subduction zone to 502 another.

\section{Conclusion}

In nature, subduction zone faults are more complicated than what is depicted in our numerical models (fault roughness, multiple asperities, off-fault inelastic deformation etc.). In particular, our choice of type of initial stress distribution (i.e. an 'asperity' model) only examines a small part of the potential stress models and it

509 might not be compatible with stress profiles derived from the modelling of the whole 510 seismic cycle. Therefore, future work should focus on the application of the model to 511 a much wider range of heterogeneous initial stress conditions.

513 law tuned to the 2011 Tohoku fault region allows us to better understand and

514 reproduce to the first order the different types of (tsunamigenic) earthquakes.

515 Consistently with geophysical observations, the numerical simulations have shown 516 that events with a number of characteristics resembling tsunami earthquakes were 517 generated either near to or below the accretionary wedge. Their rupture area was 518 constrained to remain there due to the fault strength and breakdown energy increasing 519 with depth. We also found that standard thrust earthquakes, with relatively larger 520 stress drops, shorter durations and faster rupture velocities occurred in crystalline rock 521 where both the energy release rate and fault resistance are high. Finally, if the rupture 522 initiated at the bottom of or just below the rock-clay transition and propagated 523 towards the surface and into a zone characterised by low fault strength and frictional 524 resistance, this leads to the production of great thrust earthquakes. 


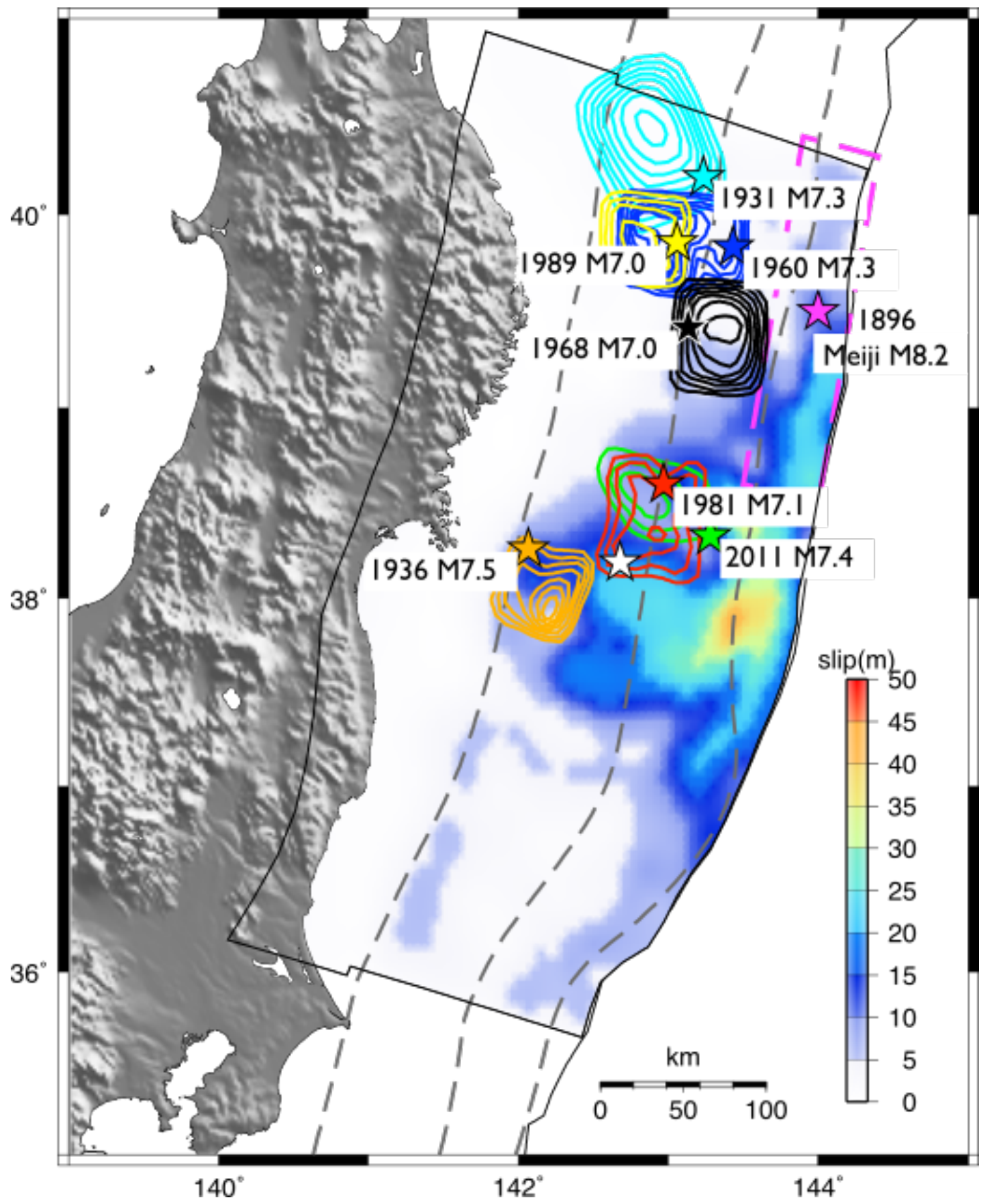

530 Figure 1: Earthquake history off the Pacific coast of Tohoku region and model setup.

531 Coloured contours represent slip distributions at $0.5 \mathrm{~m}$ interval for a number of 
historical thrust earthquakes(Shao et al., 2011; Yamanaka and Kikuchi, 2004); The magenta dashed box represents the location for the 1896 Meiji tsunami earthquakes

534 (M 8.2-8.4). The colour slip distribution is the $\mathrm{M}_{\mathrm{w}} 9$ Tohoku earthquake(Romano et 535 al., 2014), the red star is its epicentre. Dashed grey line is depth at 10, 20 and $40 \mathrm{~km}$.
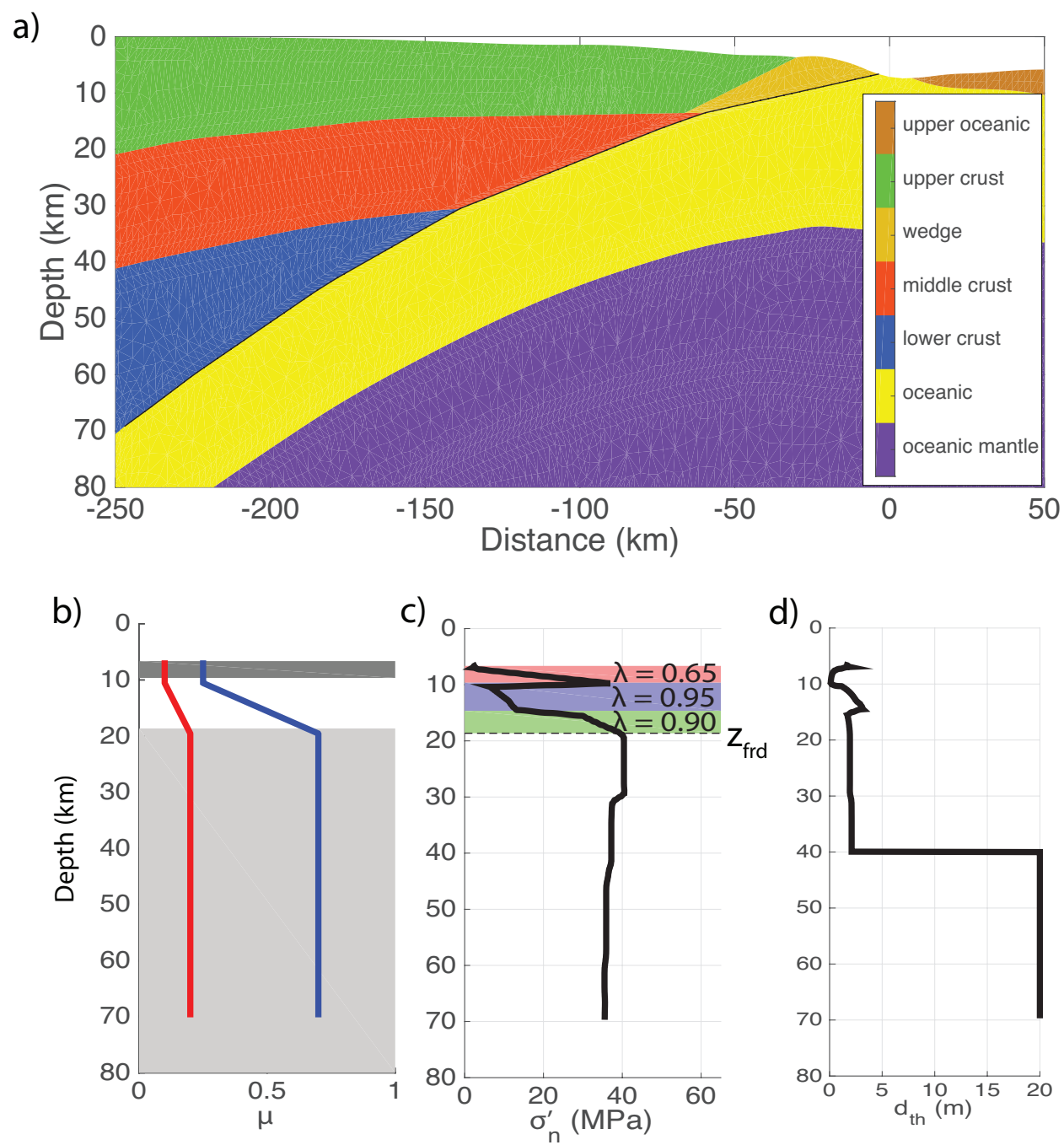

d)

539 Figure 2: Numerical model set up. a) structural model used in the numerical

540 simulations, black line denotes the subduction interface. b) variation of frictional

541 coefficients with depth: the dark and light grey boxes denote the clay-rich and

542 crystalline rock frictional coefficients; the white is the transition between the two 
543 materials. Solid blue and red lines are the static and dynamic coseismic coefficients of

544 friction respectively. c) the variation of the effective normal stress with depth,

545 coloured boxes denote different pore fluid to overburden stress ratio, $\lambda$. The dashed

546 black line denotes the fluid retention depth. d) variance of $\mathrm{d}_{\mathrm{th}}$ with depth which is a

547 function of effective normal stress and frictional material type (i.e., rock or clay-rich).

548

549

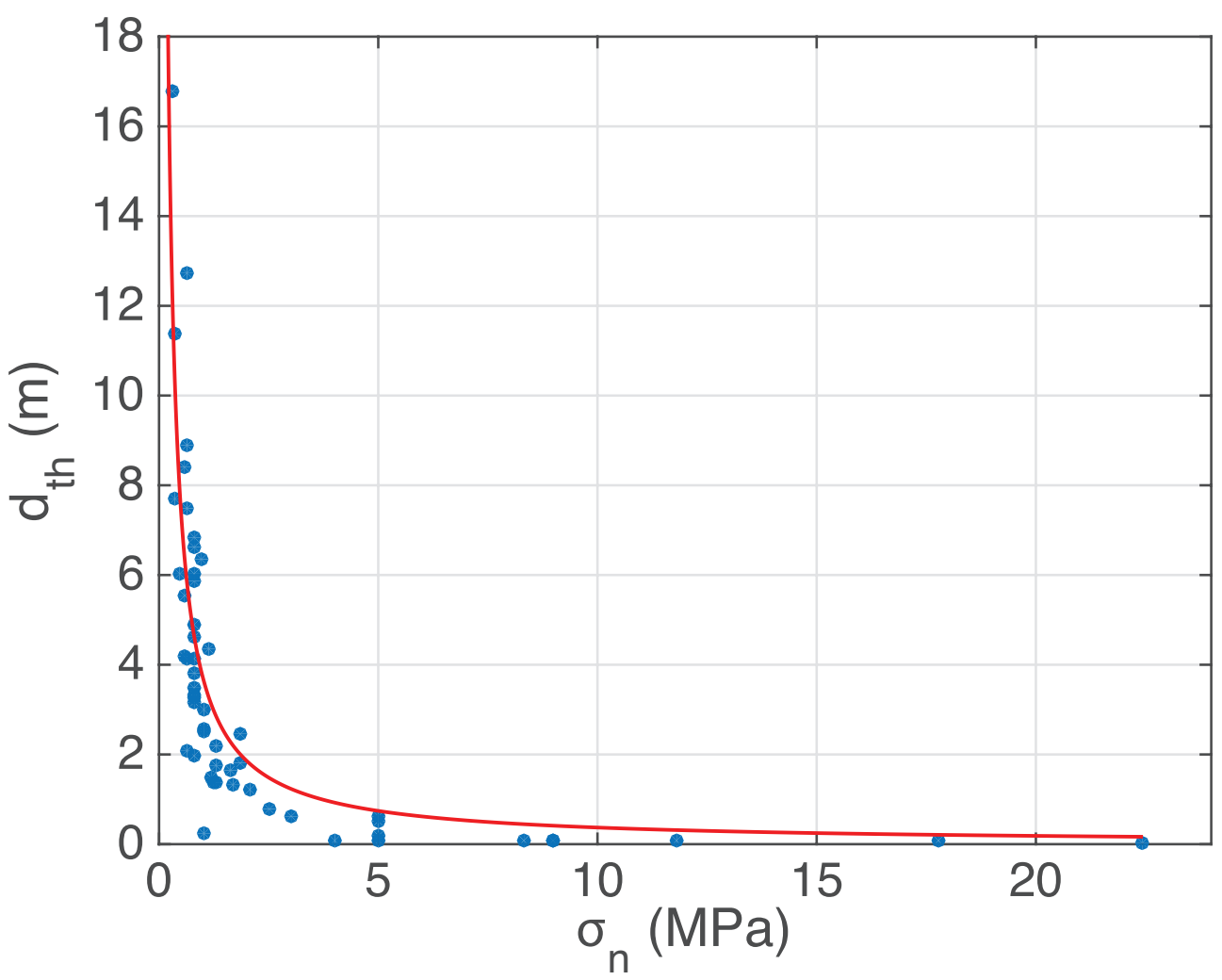

550

551 Figure 3: The fit of $d_{t h}=3.712\left\|\sigma_{n}\right\|^{-1}$ (red line) compared with the laboratory

552 experiments performed on clay material (see Table S5 in Supplementary Material for 553 references).

554

555 
a)
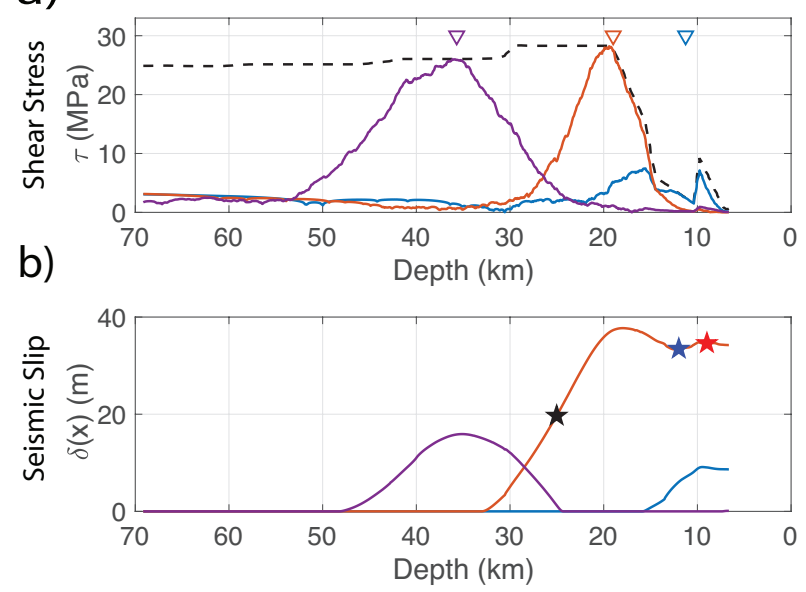

C)

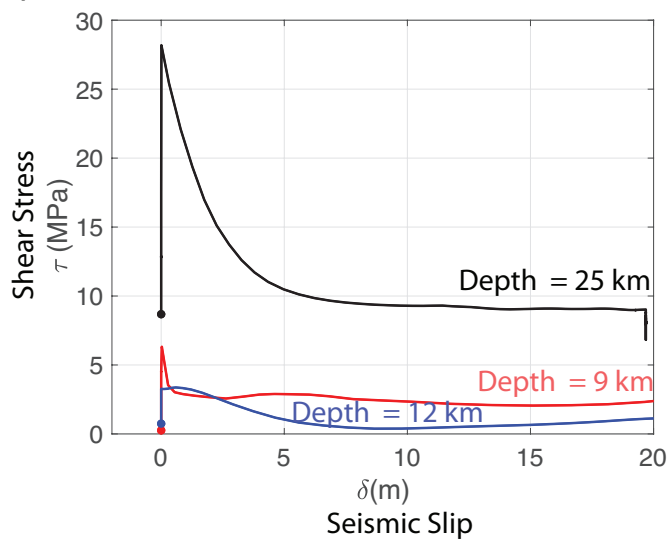

Figure 4: Modelled environment earthquake source parameters a) The different solid colours relate to the initial shear stress distributions used in the three simulations which reproduce a tsunamigenic great thrust earthquake (orange), tsunami earthquake

560 (blue) and thrust earthquakes (purple). The same colour code is used for all subplots.

561 Triangles are nucleation locations. Black dashed line is the fault strength. b) Slip

562 distributions resulting from simulations where the colours relate to the initial stress

563 distributions in a). c) Shear stress evolution with slip at three different depths $(25 \mathrm{~km}$

564 black line, $12 \mathrm{~km}$ blue line, $9 \mathrm{~km}$ red line) taken from intermediate simulation (i.e.,

565 orange line in $b$ ). The locations are also highlighted by stars in subplot $b$ ) where a

566 similar colour scale has been used. Dots denote the initial stress at each location. 
a)

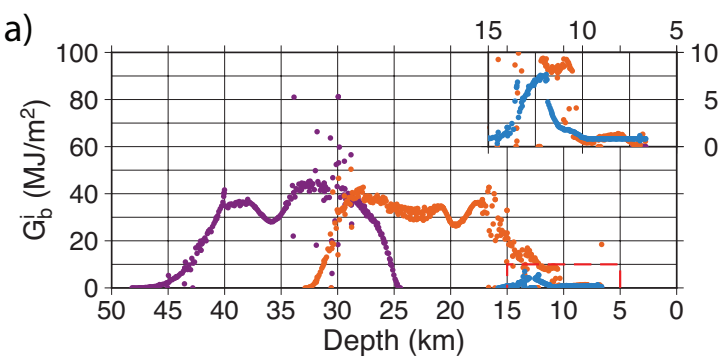

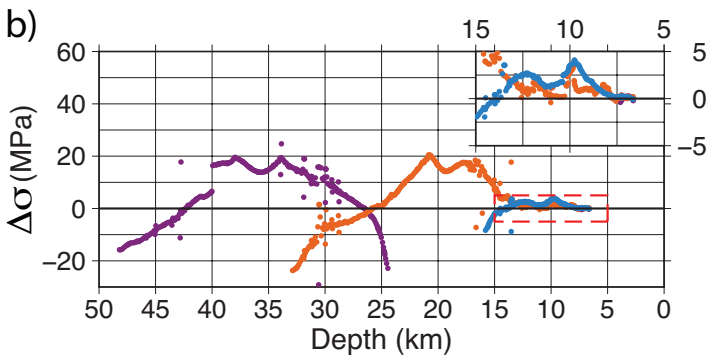

573 Figure 5: a) Breakdown energy calculated at each point along the fault. Insets are

574 expansions of the data inside the red dashed boxes. b) Static stress drop calculated at 575 each point along the fault.

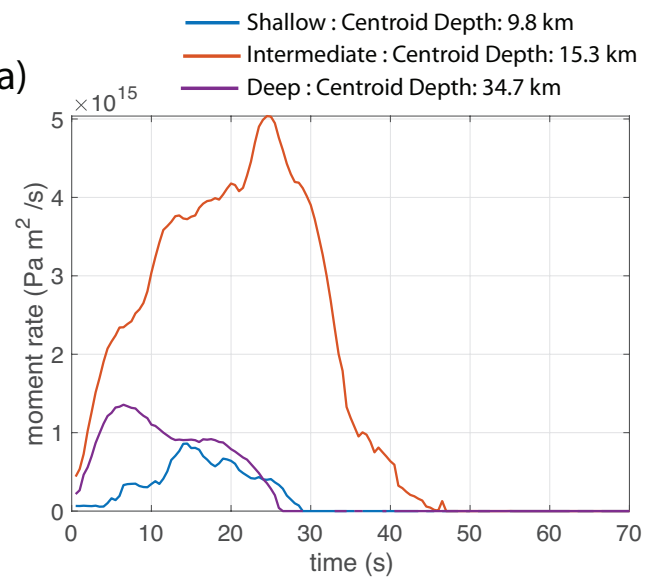

b)

580 Figure 6: a) Moment release rate with time. b) Vertical seafloor displacement (dotted

581 lines) and estimated tsunami source (solid lines, details in Section A3 in

582 Supplementary Information). Horizontal distance as in Fig. 2 where $0 \mathrm{~km}$ indicates the point where the fault reaches the seafloor. 


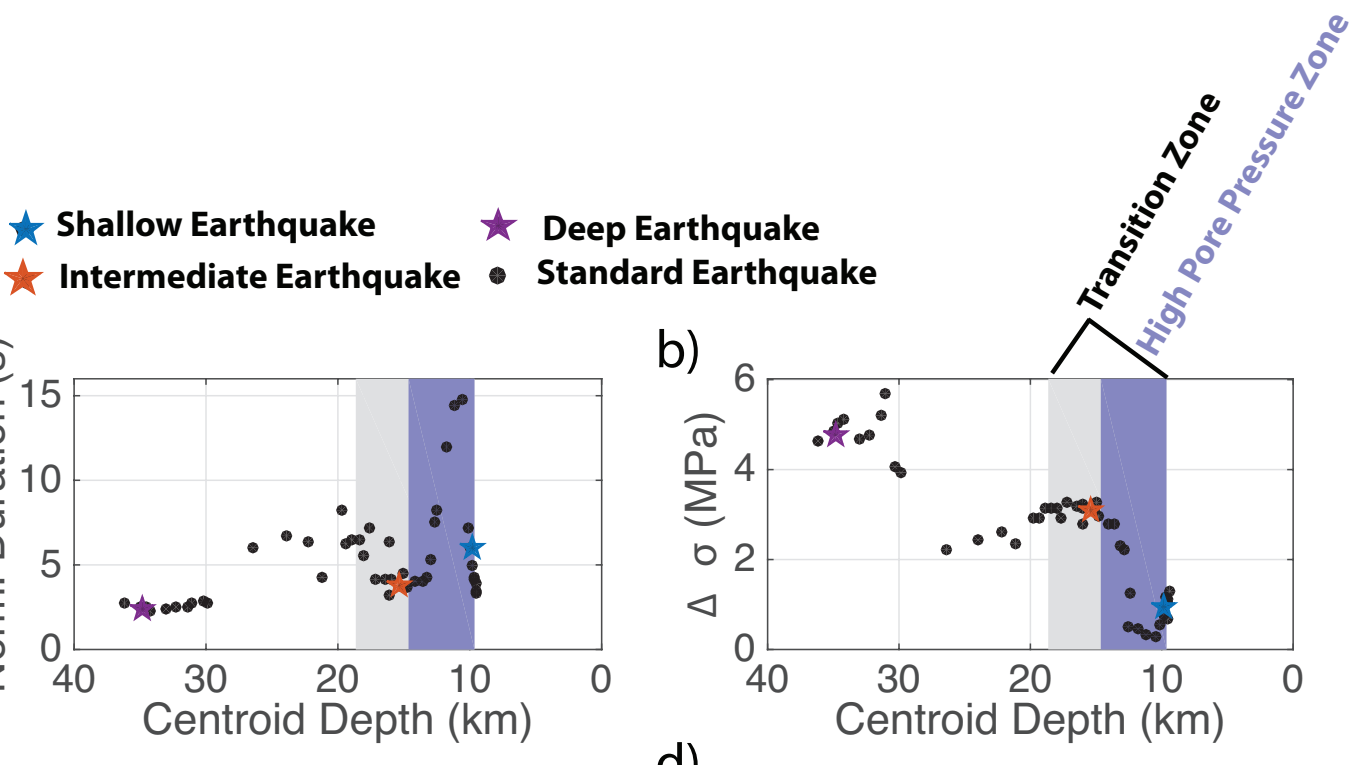

c)

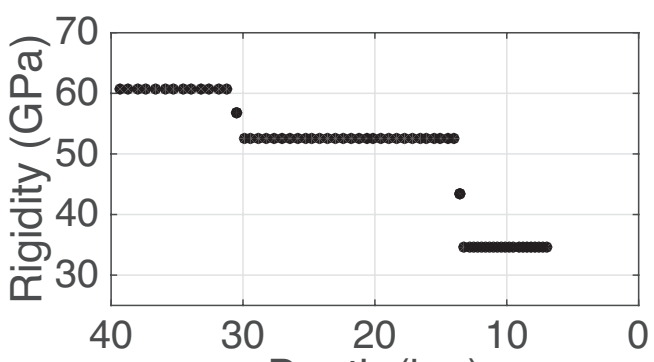

e)

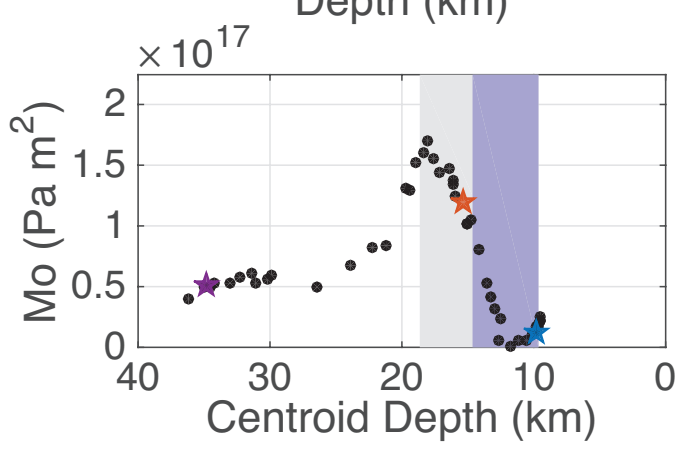

d)

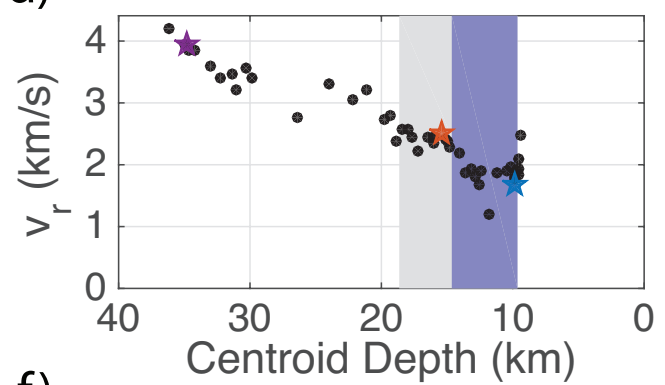

f)

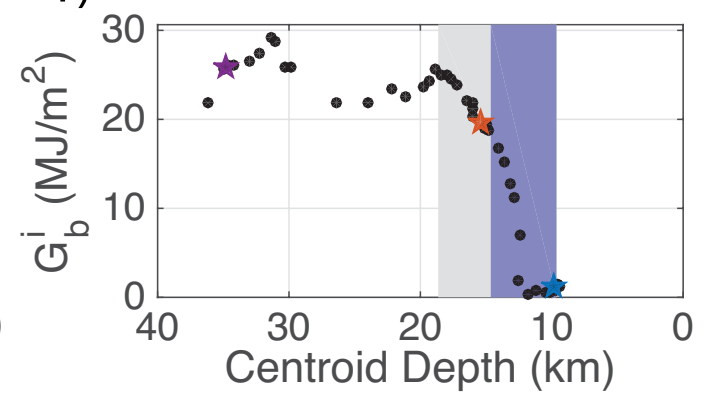

Figure 7: Rupture parameters plotted against centroid depth for a number of simulations where only the location of the high stress asperity varies with depth. The

589 purple box is the zone with very high pore pressure $(\lambda=0.95)$; grey and purple boxes

590 together demark the transition zone between clay-like and crystalline rock frictional

591 parameters. a) Normalised earthquake duration; b) Average static stress drop; c) shear 592 modulus averaged across the fault plane to account of bi-material wall rocks; d)

593 Average rupture velocity; e) Moment of the (1D) simulated earthquakes (details in 
Section A4 in Supplementary Material); and f) Average breakdown energy. The stars indicate the three case studies presented in Fig. 2 with the same colour code applied.

(a)

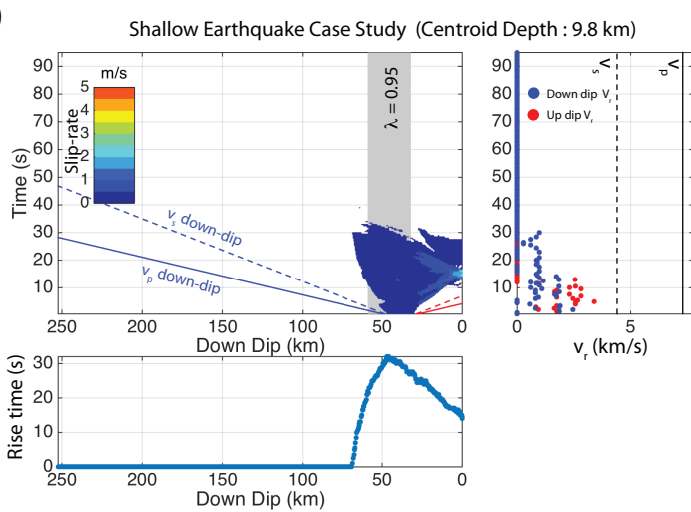

(c)
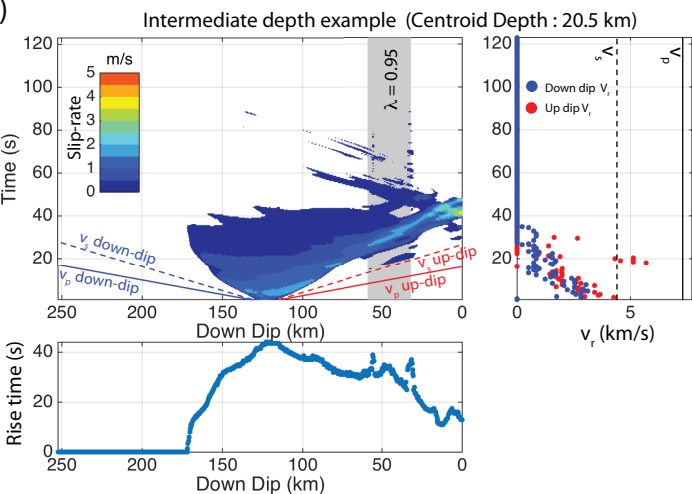

(b)

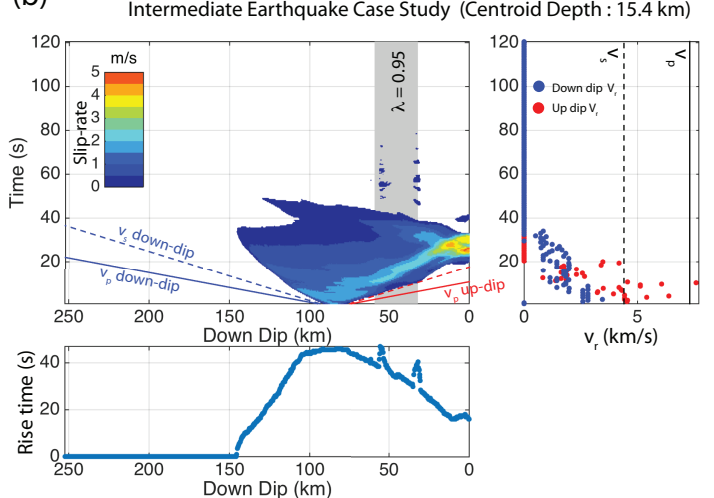

(d)
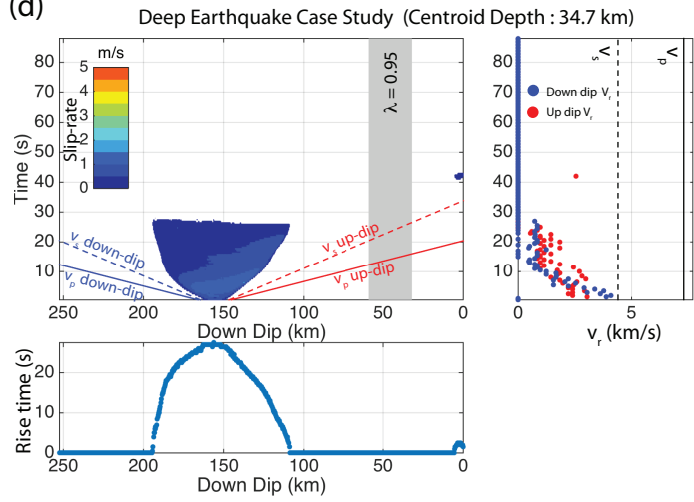

Figure 8: Slip-rate, rupture velocity and rise-time observed in four simulations with increasing fault down-dip location of the asperity (40,80, 120 and $160 \mathrm{~km}$ depth, respectively). These depths correspond to the hypocentral depths of the three cases presented in Fig. 2 and an additional great thrust earthquake which generated a down604 dip travelling rupture pulse. In all subplots the solid and dashed lines are the P-and S605 wave velocities in the oceanic material (i.e., yellow layer in Fig. 1) with the colour of the line indicating rupture direction (i.e. blue is to the left of the nucleation zone or down-dip, red is the right or up-dip). The light grey box behind the slip-rates defines the zone of very high pore pressure (i.e., $\lambda=0.95$ ) in the wedge. a) Asperity in the 
609 wedge which corresponds to the shallow case study (blue line and dots in Figs. 2 and

610 3) b) Asperity at $20 \mathrm{~km}$ depth related to the intermediate case study (i.e., orange data

611 in Figs. 2 and 3). c) Asperity at $27 \mathrm{~km}$ depth, an example of a great thrust earthquake

612 with a down-dip travelling rupture pulse that was referred to in Section 3.4 d) Deep

613 case study (i.e., $39 \mathrm{~km}$ ) purple colour in Figs. 2 and 3.

614

615

616

a)

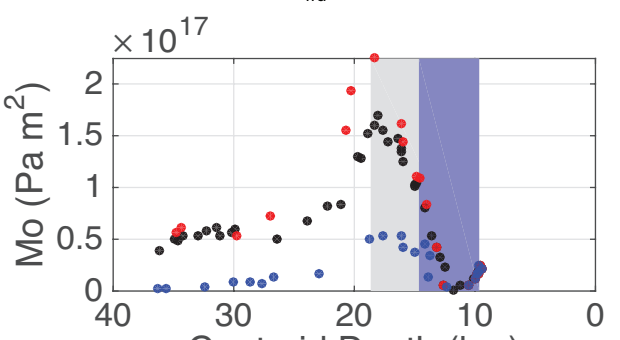

c)

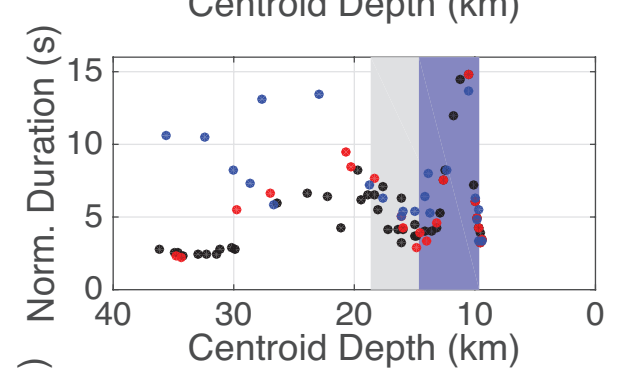

e)

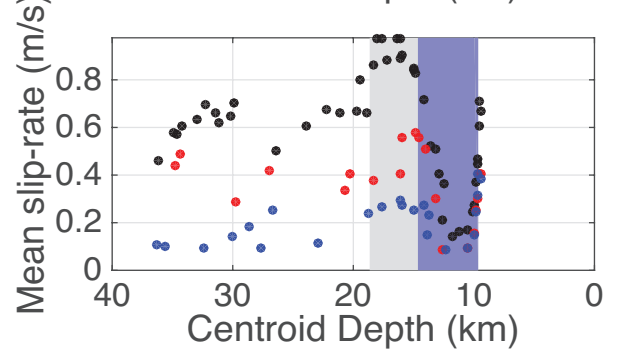

- $\mathrm{z}_{\mathrm{frd}}=7 \mathrm{~km}$

- $z_{\text {frd }}=12 \mathrm{~km}$ ( original set up )

- $\mathrm{z}_{\mathrm{frd}}=17 \mathrm{~km}$

b)

d)
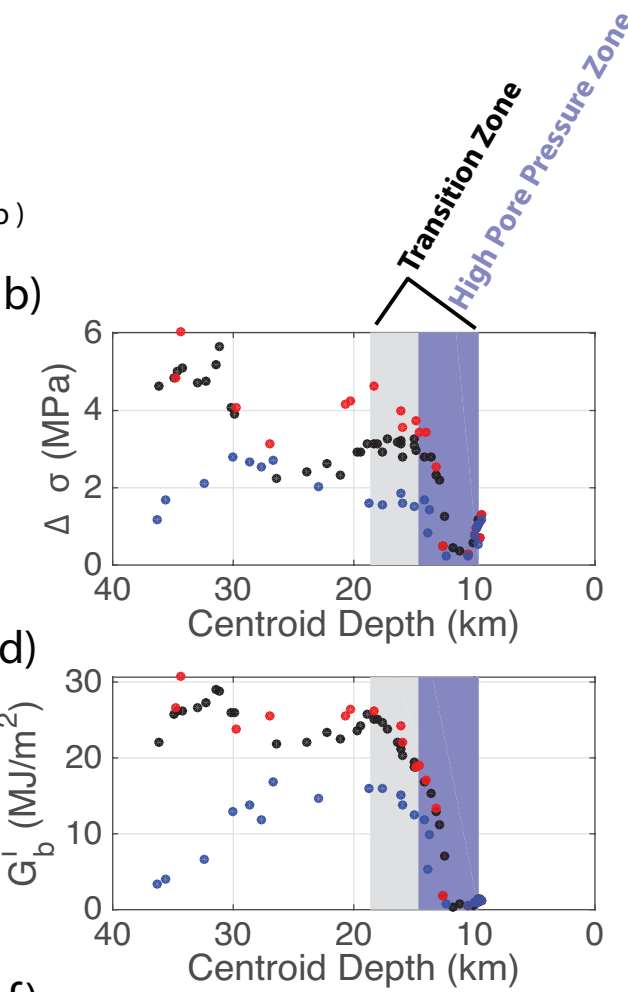

f)

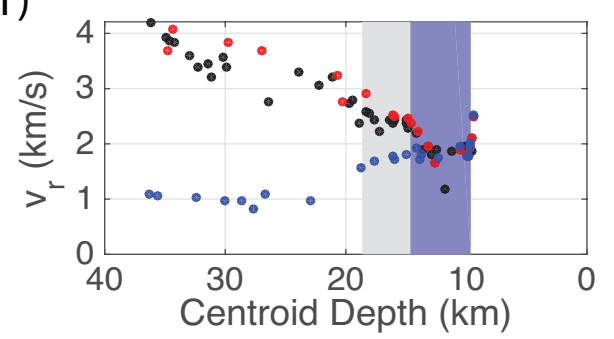

618 Figure 9: Sensitivity study on varying the fluid retention depth. The black dots are

619 from simulations using the original model discussed in Section 3 (i.e., $\mathrm{Z}_{\mathrm{FRD}}=12 \mathrm{~km}$ ) 
620 with 45 simulations, the blue dots are the case $\mathrm{z}_{\mathrm{FRD}}=7 \mathrm{~km}$ (15 simulations) and the

621 red dots are case with $\mathrm{Z}_{\mathrm{FRD}}=17 \mathrm{~km}$ (15 simulations). a) Seismic moment of the

622 simulated earthquake; a constant shear modulus $G=30 \mathrm{GPa}$ rather than a depth

623 dependent shear modulus was used in the calculation as it is commonly used in

624 observational seismology, b) Average static stress drop, c) average normalised rupture

625 duration, d) average breakdown energy, e) average slip-rate per earthquake and f)

626 average rupture velocity.

627
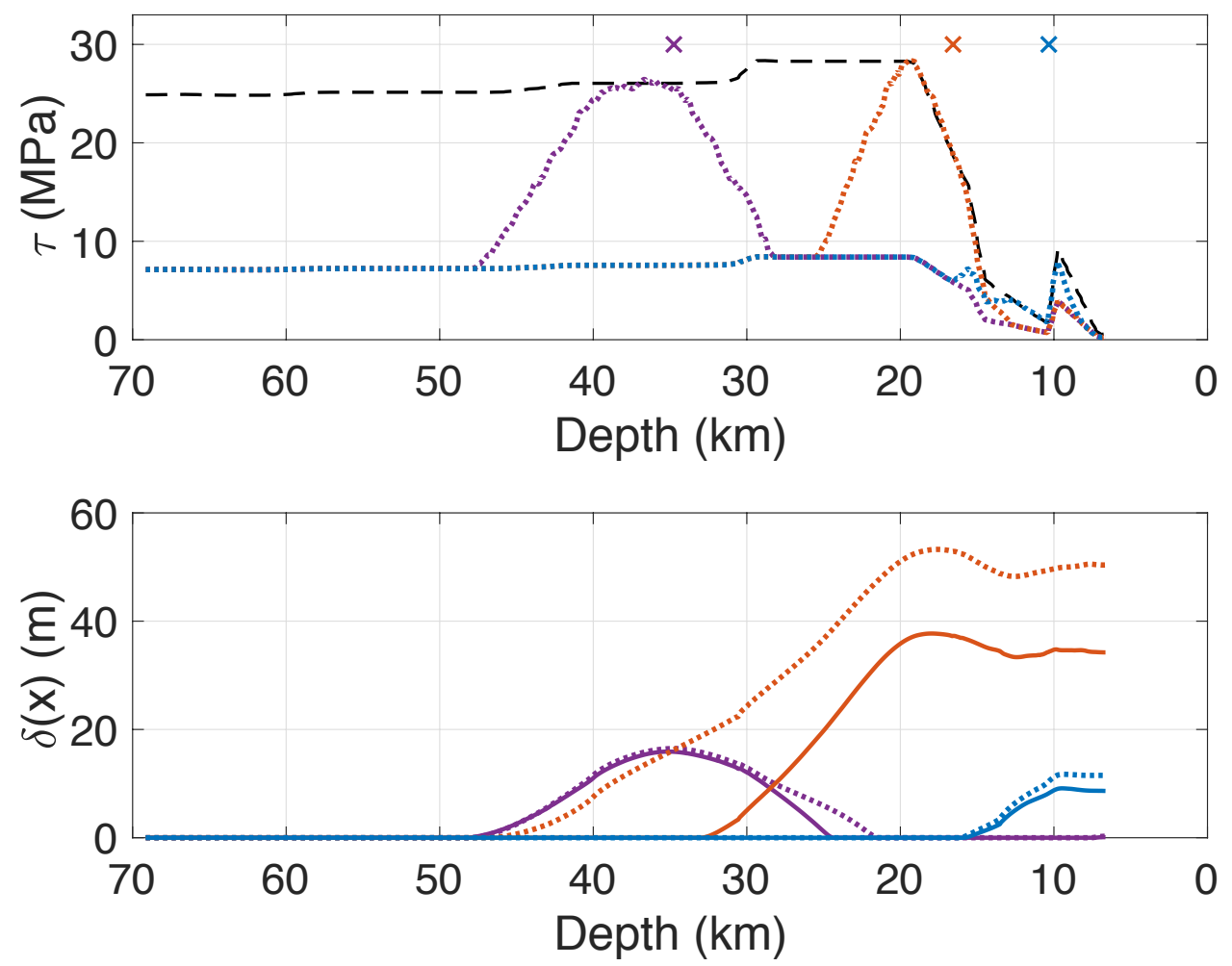

628

629 Figure 10: Testing increased background initial stress outside of the asperity. a) The

630 black dashed line is the yield strength. The dotted colour lines represent the initial

631 shear stress where stress does not drop below the residual shear stress (i.e. $\tau=\mu_{d} \sigma_{n}$ ).

632 The x's are the nucleation locations for the new (i.e. dashed) set of simulations. b) the

633 final slip distributions for each simulation where the colour and line type convention 
is same as the one used in subplot a) The solid lines are the slip distributions using the

original initial stress distribution (see Fig. 4).

\section{References}

639

640

641

642

643

644

645

646

647

648

649

650

651

652

653

654

655

656

657

658

659

660

661

662

663

664

665

666

667

668

669

670

671

672

673

674

675

676

677

678

Abercrombie, R., Rice, J., 2005. Can observations of earthquakes scaling constrain slip weakening. Geophys. J. Int. 162, 406-424. doi:10.1111/j.1365246X.2005.02579.x

Ammon, C.J., Kanamori, H., Lay, T., Velasco, A.A., 2006. The 17 July 2006 Java tsunami earthquake. Geophys. Res. Lett 33, L24308-5. doi:10.1029/2006GL028005

Bilek, S.L., Lay, T., 1999. Rigidity variations with depth along interplate megathrust faults in subduction zones. Nature 400, 443-446. doi:10.1038/22739

Bilek, S.L., Rotman, H.M.M., Phillips, W.S., 2016. Low stress drop earthquakes in the rupture zone of the 1992 Nicaragua tsunami earthquake. Geophys. Res. Lett 43, 10,180-10,188. doi:10.1002/2016GL070409

Brace, W.F., Kohlstedt, D.L., 1980. Limits on lithospheric stress imposed by laboratory experiments. J. Geophys. Res. 85, 6248-6252. doi:10.1029/JB085iB11p06248

Chester, F.M., Rowe, C., Ujiie, K., Kirkpatrick, J., Regalla, C., Remitti, F., Moore, J.C., Toy, V., Wolfson-Schwehr, M., Bose, S., Kameda, J., Mori, J.J., Brodsky, E.E., Eguchi, N., Toczko, S., Expedition 343 and 343T Scientists, 2013. Structure and Composition of the Plate-Boundary Slip Zone for the 2011 Tohoku-Oki Earthquake. Science 342, 1208-1211. doi:10.1126/science.1243719

Chu, R., Wei, S., Helmberger, D.V., Zhan, Z., Zhu, L., Kanamori, H., 2011. Initiation of the great Mw 9.0 Tohoku-Oki earthquake. Earth Planet. Sci. Lett. 308, 277283. doi:10.1016/j.eps1.2011.06.031

Cochard, A., Madariaga, R., 1996. Complexity of seismicity due to highly ratedependent friction. J. Geophys. Res. 101, 25,321-25,336.

Cubas, N., Lapusta, N., Avouac, J.-P., Perfettini, H., 2015. Numerical modeling of long-term earthquake sequences on the NE Japan megathrust: Comparison with observations and implications for fault friction. Earth Planet. Sci. Lett. 419, 187198. doi:10.1016/j.epsl.2015.03.002

Del Gaudio, P., Di Toro, G., Han, R., Hirose, T., Nielsen, S., Shimamoto, T., Cavallo, A., 2009. Frictional melting of peridotite and seismic slip. J. Geophys. Res. 114, B06306-19. doi:10.1029/2008JB005990

Di Toro, G., Han, R., Hirose, T., De Paola, N., Nielsen, S., Mizoguchi, K., Ferri, F., Cocco, M., Shimamoto, T., 2011. Fault lubrication during earthquakes. Nature 471, 494-498. doi:10.1038/nature09838

Dieterich, J., 1979. Modeling of Rock Friciton: 1. Experimental results and constituive equations. J. Geophys. Res. 84, 2161-2168.

Faulkner, D.R., Mitchell, T.M., Behnsen, J., Hirose, T., Shimamoto, T., 2011. Stuck in the mud? Earthquake nucleation and propagation through accretionary forearcs. Geophys. Res. Lett 38. doi:10.1029/2011GL048552

Festa, G., Vilotte, J.-P., 2005. The Newmark scheme as velocity-stress time- 
staggering: an efficient PML implementation for spectral element simulations of elastodynamics. Geophys. J. Int. 161, 789-812. doi:10.1111/j.1365246X.2005.02601.X

Festa, G., and J.-P. Vilotte 2006, Influence of the rupture initiation on the intersonic transition: Crack-like versus pulse-like modes, Geophys. Res. Lett, 33 (L15320), doi:http://dx.doi.org/10.1029/2006GL026378.

Freed, A., 2005. Earthquake triggering by static, dynamic, and postseismic stress transfer. Annu. Rev. Earth Planet Sci. 33, 335-367. doi:http://dx.doi.org/10.1146/annurev.earth.33.092203.122505

Gao, X., Wang, K., 2014. Strength of stick-slip and creeping subduction megathrusts from heat flow observations. Science 345, 1038-1041. doi:10.1126/science. 1255487

Geist, E.L., Bilek, S.L., 2001. Effect of depth-dependent shear modulus on tsunami generation along subduction zones. Geophys. Res. Lett 28, 1315-1318. doi:10.1029/2000GL012385

Grezio, A., Babeyko, A., Baptista, M. A., Behrens, J., Costa, A., Davies, G., Geist, E. L., Glimsdal, S., González, F. I., Griffin, J., Harbitz, C. B., LeVeque, R. J., Lorito, S., Løvholt, F., Omira, R., Mueller, C., Paris, R., Parsons, T., Polet, J., Power, W., Selva, J., Sørensen M., B., Thio, H. K. 2017. Probabilistic Tsunami Hazard Analysis: Multiple sources and global applications. Reviews of Geophysics, 55. doi: 10.1002/2017RG000579

Hacker, B.R., Abers, G.A., Peacock, S.M., 2003a. Subduction factory 1. Theoretical mineralogy, densities, seismic wave speeds, and $\mathrm{H} 2 \mathrm{O}$ contents. J Geophys Res 108, 1-26. doi:10.1029/2001JB001127

Hacker, B.R., Peacock, S.M., Abers, G.A., Holloway, S.D., 2003b. Subduction factory 2. Are intermediate-depth earthquakes in subducting slabs linked to metamorphic dehydration reactions? J. Geophys. Res. 108, 1-20. doi:10.1029/2001JB001129

Hartog, den, S.A.M., Niemeijer, A.R., Spiers, C.J., 2012. New constraints on megathrust slip stability under subduction zone P-T conditions. Earth and Planetary Science Letters 353-354, 240-252. doi:10.1016/j.eps1.2012.08.022

Hayes, G.P., Wald, D.J., Johnson, R.L., 2012. Slab1.0: A three-dimensional model of global subduction zone geometries. J. Geophys. Res. 117, B01302-15. doi:10.1029/2011JB008524

Hirono, T., Ishikawa, T., Masumoto, H., Kameda, J., Yabuta, H., Mukoyoshi, H., 2014. Re-evaluation of frictional heat recorded in the dark gouge of the shallow part of a megasplay fault at the Nankai Trough. Tectonophysics 626, 157-169. doi:10.1016/j.tecto.2014.04.020

Hirono, T., Tsuda, K., Tanikawa, W., Ampuero, J.-P., Shibazaki, B., Kinoshita, M., Mori, J.J., 2016. Near-trench slip potential of megaquakes evaluated from fault properties and conditions. Sci. Rep. 1-13. doi:10.1038/srep28184

Huang, Y., Ampuero, J.-P., Kanamori, H., 2013. Slip-Weakening Models of the 2011 Tohoku-Oki Earthquake and Constraints on Stress Drop and Fracture Energy. Pure Appl. Geophys. 171, 2555-2568. doi:10.1007/s00024-013-0718-2

Hyndman, R., Yamano, M., Oleskevich, D., 1997. The seismogenic zone of subduction thrust faults. The Island Arc 6, 244-260.

Ida, Y., 1972. Cohesive Force across the Tip of a Longitudinal-Shear Crack and Griffith's Specific Surface Energy. J. Geophys. Res. 77, 3796-3805.

Ide, S., Baltay, A., Beroza, G.C., 2011. Shallow Dynamic Overshoot and Energetic Deep Rupture in the 2011 Mw 9.0 Tohoku-Oki Earthquake. Science 332, 1426- 
Ihmlé, P.F., 1996. Monte Carlo slip inversion in the frequency domain:: Application to the 1992 Nicaragua Slow Earthquake. Geophys. Res. Lett 23, 913-916. doi:10.1029/96GL00872

Ikari, M.J., Saffer, D.M., Marone, C., 2007. Effect of hydration state on the frictional properties of montmorillonite-based fault gouge. J. Geophys. Res. 112, B0642312. doi: $10.1029 / 2006 J$ B004748

Kanamori, H., 1972. Mechanism of tsunami earthquakes. Phys. Earth Planet. In. 6, 346-359. doi:10.1016/0031-9201(72)90058-1

Kato, N., 2012. Dependence of earthquake stress drop on critical slip-weakening distance. J Geophys Res 117. doi:10.1029/2011JB008359

Kimura, G., Hina, S., Hamada, Y., Kameda, J., Tsuji, T., Kinoshita, M., Yamaguchi, A., 2012. Runaway slip to the trench due to rupture of highly pressurized megathrust beneath the middle trench slope: The tsunamigenesis of the 2011 Tohoku earthquake off the east coast of northern Japan. Earth Planet. Sci. Lett. 339-340, 32-45. doi:10.1016/j.epsl.2012.04.002

Kozdon, J.E., Dunham, E.M., 2014. Constraining shallow slip and tsunami excitation in megathrust ruptures using seismic and ocean acoustic waves recorded on ocean-bottom sensor networks. Earth Planet. Sci. Lett. 396, 56-65. doi:10.1016/j.epsl.2014.04.001

Kozdon, J.E., Dunham, E.M., 2013. Rupture to the Trench: Dynamic Rupture Simulations of the 11 March 2011 Tohoku Earthquake. B. Seismol. Soc. Am. 103, 1275-1289. doi:10.1785/0120120136

Lay, T., Kanamori, H., Ammon, C.J., Koper, K.D., Hutko, A.R., Ye, L., Yue, H., Rushing, T.M., 2012. Depth-varying rupture properties of subduction zone megathrust faults. J. Geophys. Res. 117, B04311-21. doi:10.1029/2011JB009133

Lorito, S., Romano, F., \& Lay, T., 2016. Tsunamigenic earthquakes (2004-2013): Source processes from data inversion. In R. Meyers (Ed.), Encyclopedia of complexity and systems science. New York: Springer Science+Business Media New York 2015. doi: 10.1007/978-3-642-27737-5641-1

Lotto, G.C., Dunham, E.M., Jeppson, T.N., Tobin, H.J., 2017. The effect of compliant prisms on subduction zone earthquakes and tsunamis. Earth Planet. Sci. Lett. 458, 213-222. doi:10.1016/j.eps1.2016.10.050

Ma, S., 2012. A self-consistent mechanism for slow dynamic deformation and tsunami generation for earthquakes in the shallow subduction zone. Geophys. Res. Lett 39, n/a-n/a. doi:10.1029/2012GL051854

Meneghini, F., Di Toro, G., Rowe, C.D., Moore, J.C., Tsutsumi, A., Yamaguchi, A., 2010. Record of mega-earthquakes in subduction thrusts: The black fault rocks of Pasagshak Point (Kodiak Island, Alaska). Geol. Soc. Am. Bull. 122, 1280-1297. doi:10.1130/B30049.1

Mitsui, Y., Yagi, Y., 2013. An interpretation of tsunami earthquake based on a simple dynamic model: Failure of shallow megathrust earthquake. Geophys. Res. Lett 40, 1523-1527. doi:10.1002/grl.50266

Miura, S., Takahashi, N., Nakanishi, A., Tsuru, T., Kodaira, S., Kaneda, Y., 2005. Structural characteristics off Miyagi forearc region, the Japan Trench seismogenic zone, deduced from a wide-angle reflection and refraction study. Tectonophysics 407, 165-188. doi:10.1016/j.tecto.2005.08.001

Murphy, S., Nielsen, S., 2009. Estimating earthquake magnitude with early arrivals: A test using dynamic and kinematic models. B. Seismol. Soc. Am. 99, No. 1, 1-23. doi:http://dx.doi.org/10.1785/0120070246 
Murphy, S., Scala, A., Herrero, A., Lorito, S., Festa, G., Trasatti, E., Tonini, R., Romano, F., Molinari, I., Nielsen, S., 2016. Shallow slip amplification and enhanced tsunami hazard unravelled by dynamic simulations of mega-thrust earthquakes. Sci. Rep. 1-12. doi:10.1038/srep35007

Nalbant, S., McCloskey, J., Steacy, S., NicBhloscaidh, M., Murphy, S., 2013. Interseismic coupling, stress evolution, and earthquake slip on the Sunda megathrust. Geophys. Res. Lett 40, 4204-4208. doi:10.1002/grl.50776

Nielsen, S., Carlson, J., 2000. Rupture Pulse Characterization: Self-Healing, SelfSimilar, Expanding Solutions in a Continuum Model of Fault Dynamic. B. Seismol. Soc. Am. 90, No. 6, 1480-1497.

Nielsen, S., Mosca, P., Giberti, G., Di Toro, G., Hirose, T., Shimamoto, T., 2010. On the transient behavior of frictional melt during seismic slip. J. Geophys. Res. 115, B10301-17. doi:10.1029/2009JB007020

Nielsen, S., Spagnuolo, E., Violay, M., Smith, S., Toro, G., Bistacchi, A., 2016. G: Fracture energy, friction and dissipation in earthquakes. J. Seismol. 1-19. doi:10.1007/s10950-016-9560-1

Nielsen, S.B., 1998. Free surface effects on the propagation of dynamic rupture. Geophys. Res. Lett. 25, 125-128.

Niemeijer, A., Di Toro, G., Nielsen, S., Di Felice, F., 2011. Frictional melting of gabbro under extreme experimental conditions of normal stress, acceleration, and sliding velocity. J. Geophys. Res. 116. doi:10.1029/2010JB008181

Noda, H., Lapusta, N., 2013. Stable creeping fault segments can become destructive as a result of dynamic weakening. Nature 493, 518-521. doi:10.1038/nature11703

Oglesby, D., Archuleta, R., Nielsen, S., 1998. Earthquakes on Dipping Faults: The Effects of Broken Symmetry. Science 280, 1055-1059. doi:http://dx.doi.org/10.1126/science.280.5366.1055

Ozawa, S., Nishimura, T., Suito, H., Kobayashi, T., Tobita, M., Imakiire, T., 2011. Coseismic and postseismic slip of the 2011 magnitude-9 Tohoku-Oki earthquake. Nature 475, 373-376. doi:10.1038/nature10227

Proctor, B.P., Mitchell, T.M., Hirth, G., Goldsby, D., Zorzi, F., Platt, J.D., Di Toro, G., 2014. Dynamic weakening of serpentinite gouges and bare surfaces at seismic slip rates. J. Geophys. Res. 119, 8107-8131. doi:10.1002/2014JB011057

Remitti, F., Smith, S.A.F., Mittempergher, S., Gualtieri, A.F., Di Toro, G., 2015. Frictional properties of fault zone gouges from the J-FAST drilling project ( M w9.0 2011 Tohoku-Oki earthquake). Geophys. Res. Lett 42, 2691-2699. doi:10.1002/2015GL063507

Romano, F., Trasatti, E., Lorito, S., Piromallo, C., Piatanesi, A., Ito, Y., Zhao, D., Hirata, K., Lanucara, P., Cocco, M., 2014. Structural control on the Tohoku earthquake rupture process investigated by $3 \mathrm{D}$ FEM, tsunami and geodetic data. Sci. Rep. 4. doi:10.1038/srep05631

Rubin, A.M., Ampuero, J.-P., 2007. Aftershock asymmetry on a bimaterial interface. Journal of Geophysical Research 112, B05307-23. doi:10.1029/2006JB004337

Ruina, A., 1983. Slip instablity and state variable friction law. J. Geophys. Res. 88, 10359-10370.

Saffer, D.M., Lockner, D.A., McKiernan, A., 2012. Effects of smectite to illite transformation on the frictional strength and sliding stability of intact marine mudstones. Geophys. Res. Lett. 39, L11304. doi:10.1029/2012GL051761

Saffer, D.M., Marone, C., 2003. Comparison of smectite- and illite-rich gouge frictional properties: application to the updip limit of the seismogenic zone along subduction megathrusts. Earth Planet. Sci. Lett. 215, 219-235. 

doi:10.1016/S0012-821X(03)00424-2

Satake, K., Tanioka, Y., 1999. Sources of Tsunami and Tsunamigenic Earthquakes in Subduction Zones, in: Seismogenic and Tsunamigenic Processes in Shallow Subduction Zones. Pure Appl. Geophys. 154, 467-483. doi:10.1007/978-3-03488679-6_5

Sawai, M., Hirose, T., Kameda, J., 2014. Frictional properties of incoming pelagic sediments at the Japan Trench: implications for large slip at a shallow plate boundary during the 2011 Tohoku earthquake. Earth, Planets Space 66, 65. doi:10.1186/1880-5981-66-65

Scala, A., Festa, G., Vilotte, J.-P., 2017. Rupture dynamics along bimaterial interfaces: a parametric study of the shear-normal traction coupling. Geophys. J. Int. 209, 1. doi:10.1093/gji/ggw489

Shao, G., Ji, C., Zhao, D., 2011. Rupture process of the 9 March, $2011 \mathrm{Mw} 7.4$ Sanriku-Oki, Japan earthquake constrained by jointly inverting teleseismic waveforms, strong motion data and GPS observations. Geophys. Res. Lett. 38, L00G20. doi:10.1029/2011GL049164

Shibazaki, B., Matsuzawa, T., Tsutsumi, A., 2011. 3D modeling of the cycle of a great Tohoku-Oki earthquake, considering frictional behavior at low to high slip velocities. Gephys. Res. Lett. 38, L21305. doi: 10.1029/2011GL049308

Suppe, J., 2014. Fluid overpressures and strength of the sedimentary upper crust. J. Struct. Geol. 69, 481-492. doi:10.1016/j.jsg.2014.07.009

Tanioka, Y., Satake, K., 1996. Fault parameters of the 1896 Sanriku Tsunami Earthquake estimated from Tsunami Numerical Modeling. Geophys. Res. Lett 23, 1549-1552. doi:10.1029/96GL01479

Ujiie, K., Tanaka, H., Saito, T., Tsutsumi, A., Mori, J.J., Kameda, J., Brodsky, E.E., Chester, F.M., Eguchi, N., Toczko, S., Expedition 343 and 343T Scientists, 2013. Low Coseismic Shear Stress on the Tohoku-Oki Megathrust Determined from Laboratory Experiments. Science 342, 1211-1214. doi:10.1126/science.1243485

Violay, M., Di Toro, G., Gibert, B., Nielsen, S., Spagnuolo, E., Del Gaudio, P., Azais, P., Scarlato, P.G., 2014. Effect of glass on the frictional behavior of basalts at seismic slip rates. Geophys. Res. Lett. 41, 348-355. doi:10.1002/ 2013GL058601

Wang, K., Hu, Y., 2006. Accretionary prisms in subduction earthquake cycles: The theory of dynamic Coulomb wedge. J. Geophys. Res. 111, B06410. doi:10.1029/2005JB004094

Wang, K., Hu, Y., Huene, von, R., Kukowski, N., 2010. Interplate earthquakes as a driver of shallow subduction erosion. Geology 38, 431-434. doi:10.1130/G30597.1

Yamanaka, Y., Kikuchi, M., 2004. Asperity map along the subduction zone in northeastern Japan inferred from regional seismic data. J. Geophys. Res. 109, 116. doi:10.1029/2003JB002683

Zheng, G., and Rice J., 1998. Conditions under which Velocity-Weakening Friction Allows a Self-healing versus a Cracklike Mode of Rupture, BSSA, 88, No. 6 , $1466-1483$.

Acknowledgements: S.M., G.D.T., E.S., S.N., S.A. were supported by the European Research Council Consolidator Grant Project No. 614705 NOFEAR . S.L. and A.P were supported by the European Union's Seventh Framework Programme (FP7/2007- 

2013) under grant agreement $n^{\circ} 603839$ (Project ASTARTE - Assessment, Strategy 877 and Risk Reduction for Tsunamis in Europe). All of the figures have been created 878 using either MATLAB (www.mathworks.com) and Generic Mapping Tools 879 (http://gmt.soest.hawaii.edu). Two anonymous reviewers and the Editor are 880 acknowledged for their constructive comments which further improved the paper. 881 882

883 Author Contributions: S.M. performed the numerical simulations. G.D.T., E.S., 884 S.A. and S.N. provided frictional parameters for numerical models from both 885 experiments they performed and literature. F.R. digitised slip distributions from 886 historical earthquakes. Tsunami source estimates provided by F.R. and A.S.; G.F. and 887 A.S. developed the numerical code. Concept development: S.M., G.D.T., S.L. and 888 E.S; important ideas provided by S.N., G.F. and A.P. throughout the development of 889 the work. All authors contributed to text and revised the manuscript several times.

\section{Additional Information}

892 The authors declare no competing financial interests. Correspondence and requests for 893 materials should be addressed to S.M. (shane.murphy@ifremer.fr). 


\section{Supplementary Material}

2 Title: Tsunamigenic earthquake simulations using experimentally derived friction

3 laws

4 S. Murphy ${ }^{1,2 *}$, G. Di Toro ${ }^{3,4}$, F. Romano ${ }^{1}$, A. Scala $^{1}$, S. Lorito ${ }^{1}$, E. Spagnuolo ${ }^{1}$, S.

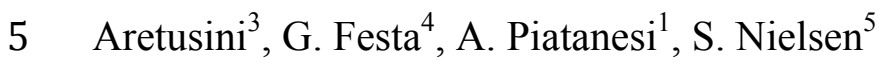

$6 \quad{ }^{1}$ Istituto Nazionale di Geofisica e Vulcanologia, Rome, Italy

$7 \quad{ }^{2}$ Ifremer, Plouzané, France

$8 \quad{ }^{3}$ University of Manchester, Manchester, United Kingdom

$9 \quad{ }^{4}$ Università degli Studi di Padova, Padua, Italy

$10 \quad{ }^{5}$ Università di Napoli Federico II, Naples, Italy

$11 \quad{ }^{6}$ Durham University, Durham United Kingdom

12 *shane.murphy@ifremer.fr

13

14 A1. Model Setup

\begin{tabular}{l|l|l|l|l} 
& $\rho\left(\mathrm{kg} / \mathrm{m}^{3}\right)$ & $v_{p}(\mathrm{~km} / \mathrm{s})$ & $v_{s}(\mathrm{~km} / \mathrm{s})$ & Colour in Fig. 1 \\
\hline Oceanic Mantle & 3300 & 8.0 & 4.6 & Purple \\
\hline Oceanic & 3000 & 7.3 & 4.4 & Yellow \\
\hline Lower Crust & 3000 & 8.0 & 4.6 & Blue \\
\hline Middle Crust & 2800 & 7.1 & 4.1 & Red \\
\hline Wedge & 2500 & 4.7 & 2.1 & Green \\
\hline Continental $/$ & 2500 & 6.2 & 3.6 & Gold \\
upper crust & & & & \\
\hline Oceanic Surface & 2800 & 7.1 & 4.4 & Brown
\end{tabular}

15 Table S1: Elastic parameters used in numerical model as depicted in Fig. 1 (main text). 


\begin{tabular}{c|c}
\hline No. of nodes per element face & 9 \\
\hline $\mathrm{dt}$ & $110^{-3} \mathrm{~s}$ \\
\hline Average element length along fault & $2.47 \mathrm{~km}$ \\
\hline Largest Courant No. & $610^{-3}$ \\
\hline
\end{tabular}

Table S2: Numerical model parameters.

20

\begin{tabular}{l|ll} 
& Clay-like & Rock-like \\
\hline$\mu_{s}$ & 0.25 & 0.7 \\
$\mu_{d}$ & 0.1 & 0.2 \\
$\alpha$ & 3.7 & 78 \\
$\beta$ & 1 & 1
\end{tabular}

21 Table S3: Frictional properties used for clay-like and rock-like materials. Rock-like

22 frictional parameters are based on Del Gaudio et al.(2009) for peridotite (note that

23 similar values are valid for gabbro, basalts and serpentinites, the most common rocks

24 of the oceanic lithosphere). The thermal slip weakening friction law produces a

25 similar evolution of stress with slip and roughly similar thermal weakening distances

26 observed in thermal pressurization modelling for the Japanese trench(Hirono et al.,

27 2016). See Methods for the clay-like materials frictional properties.

28

29

30

31 


\begin{tabular}{|c|c|c|c|c|}
\hline Run & $\boldsymbol{V}$ & $\sigma_{n}$ & $d_{t h}$ & Ref. \\
\hline & $(\mathbf{m} / \mathbf{s})$ & MPa & (m) & \\
\hline HVR784 & 1.04 & 0.28 & 16.76 & (Brantut et al., 2008) \\
\hline HVR787 & 1.04 & 0.48 & 6.01 & (Brantut et al., 2008) \\
\hline HVR782 & 1.04 & 0.59 & 5.54 & (Brantut et al., 2008) \\
\hline HVR786 & 1.04 & 0.82 & 6.84 & (Brantut et al., 2008) \\
\hline HVR781 & 1.04 & 0.99 & 6.34 & (Brantut et al., 2008) \\
\hline HVR788 & 1.04 & 1.15 & 4.37 & (Brantut et al., 2008) \\
\hline HVR780 & 1.04 & 1.32 & 1.37 & (Brantut et al., 2008) \\
\hline HVR754 & 1.04 & 0.6 & 4.17 & (Brantut et al., 2008) \\
\hline HVR905 & 1.04 & 0.62 & 2.10 & (Brantut et al., 2008) \\
\hline 1372 & 1.31 & 1 & 3.00 & (Ferri et al., 2011) \\
\hline 1868 & 1.31 & 1 & 2.50 & (Ferri et al., 2011) \\
\hline 405 & 1.3 & 9 & 0.06 & (Bullock et al., 2015) \\
\hline 395 & 1.3 & 9 & 0.07 & (Bullock et al., 2015) \\
\hline 820 & 1 & 4 & 0.07 & (Proctor et al., 2014) \\
\hline 821 & 1 & 11.8 & 0.09 & (Proctor et al., 2014) \\
\hline 822 & 1 & 17.8 & 0.06 & (Proctor et al., 2014) \\
\hline 823 & 1.1 & 22.4 & 0.05 & (Proctor et al., 2014) \\
\hline 745 & 1.2 & 8.3 & 0.08 & (Proctor et al., 2014) \\
\hline HVR178 & 1.03 & 0.66 & 7.50 & (Mizoguchi et al., 2009) \\
\hline HVR189 & 1.03 & 0.375 & 7.71 & (Mizoguchi et al., 2009) \\
\hline HVR190 & 1.03 & 0.345 & 11.39 & (Mizoguchi et al., 2009) \\
\hline HVR183 & 1.03 & 0.64 & 12.71 & (Mizoguchi et al., 2009) \\
\hline HVR184 & 1.03 & 0.636 & 8.89 & (Mizoguchi et al., 2009) \\
\hline HVR180 & 1.03 & 1.26 & 1.39 & (Mizoguchi et al., 2009) \\
\hline HVR185 & 1.03 & 1.289 & 2.20 & (Mizoguchi et al., 2009) \\
\hline HVR182 & 1.03 & 1.873 & 2.48 & (Mizoguchi et al., 2009) \\
\hline HVR188 & 1.03 & 1.856 & 1.83 & (Mizoguchi et al., 2009) \\
\hline LHV304 & 1.4 & 0.6 & 8.38 & (Yao et al., 2013a) \\
\hline LHV305 & 1.4 & 0.8 & 4.87 & (Yao et al., 2013a) \\
\hline LHV306 & 1.4 & 1 & 2.56 & (Yao et al., 2013a) \\
\hline LHV308 & 1.4 & 1.3 & 1.73 & (Yao et al., 2013a) \\
\hline LHV307 & 1.4 & 1.7 & 1.35 & (Yao et al., 2013a) \\
\hline LHV309 & 1.4 & 2.5 & 0.78 & (Yao et al., 2013a) \\
\hline LHV242 & 1.4 & 0.8 & 6.04 & (Yao et al., 2013b) \\
\hline LHV241 & 1.4 & 0.8 & 4.14 & (Yao et al., 2013b) \\
\hline LHV243 & 1.4 & 0.8 & 6.64 & (Yao et al., 2013b) \\
\hline LHV244 & 1.4 & 0.8 & 4.61 & (Yao et al., 2013b) \\
\hline LHV248 & 1.4 & 0.8 & 3.81 & (Yao et al., 2013b) \\
\hline LHV246 & 1.4 & 0.8 & 3.47 & (Yao et al., 2013b) \\
\hline LHV256 & 1.4 & 0.8 & 5.84 & (Yao et al., 2013b) \\
\hline LHV251 & 1.4 & 0.8 & 1.97 & (Yao et al., 2013b) \\
\hline LHV253 & 1.4 & 0.8 & 3.34 & (Yao et al., 2013b) \\
\hline
\end{tabular}




\begin{tabular}{|c|c|c|c|c|} 
LHV365 & 1.4 & 0.8 & 3.14 & (Yao et al., 2013b) \\
\hline HVR1489 & 1.3 & 1.01 & 0.23 & (Togo et al., 2011) \\
\hline HVR1490 & 1.3 & 0.8 & 3.25 & (Togo et al., 2011) \\
\hline HVR1491 & 1.3 & 0.61 & 4.14 & (Togo et al., 2011) \\
\hline HVR1494 & 1.3 & 1.21 & 1.51 & (Togo et al., 2011) \\
\hline HVR1496 & 1.3 & 1.64 & 1.63 & (Togo et al., 2011) \\
\hline HVR1497 & 1.3 & 2.05 & 1.22 & (Togo et al., 2011) \\
\hline HVR1502 & 1.3 & 3.04 & 0.63 & (Togo et al., 2011) \\
\hline s1168 & 1.3 & 5 & 0.18 & (Aretusini et al., 2017) \\
\hline s1167 & 1.3 & 5 & 0.10 & (Aretusini et al., 2017) \\
\hline s1166 & 1.3 & 5 & 0.64 & (Aretusini et al., 2017) \\
\hline
\end{tabular}

33 Table S4: Source of experimential data plotted in Fig. 3.

\begin{tabular}{|l|l|l|}
\hline Case Study Colour in Fig. 3 & Max. shear stress depth $(\mathrm{km})$ & Nucleation depth $(\mathrm{km})$ \\
\hline Deep & 39 & 34 \\
\hline Intermediate & 20 & 23 \\
\hline Shallow & 17 & 14.5 \\
\hline
\end{tabular}

Table S5: Model name and corresponding depth of maximum initial stress and nucleation.

40 


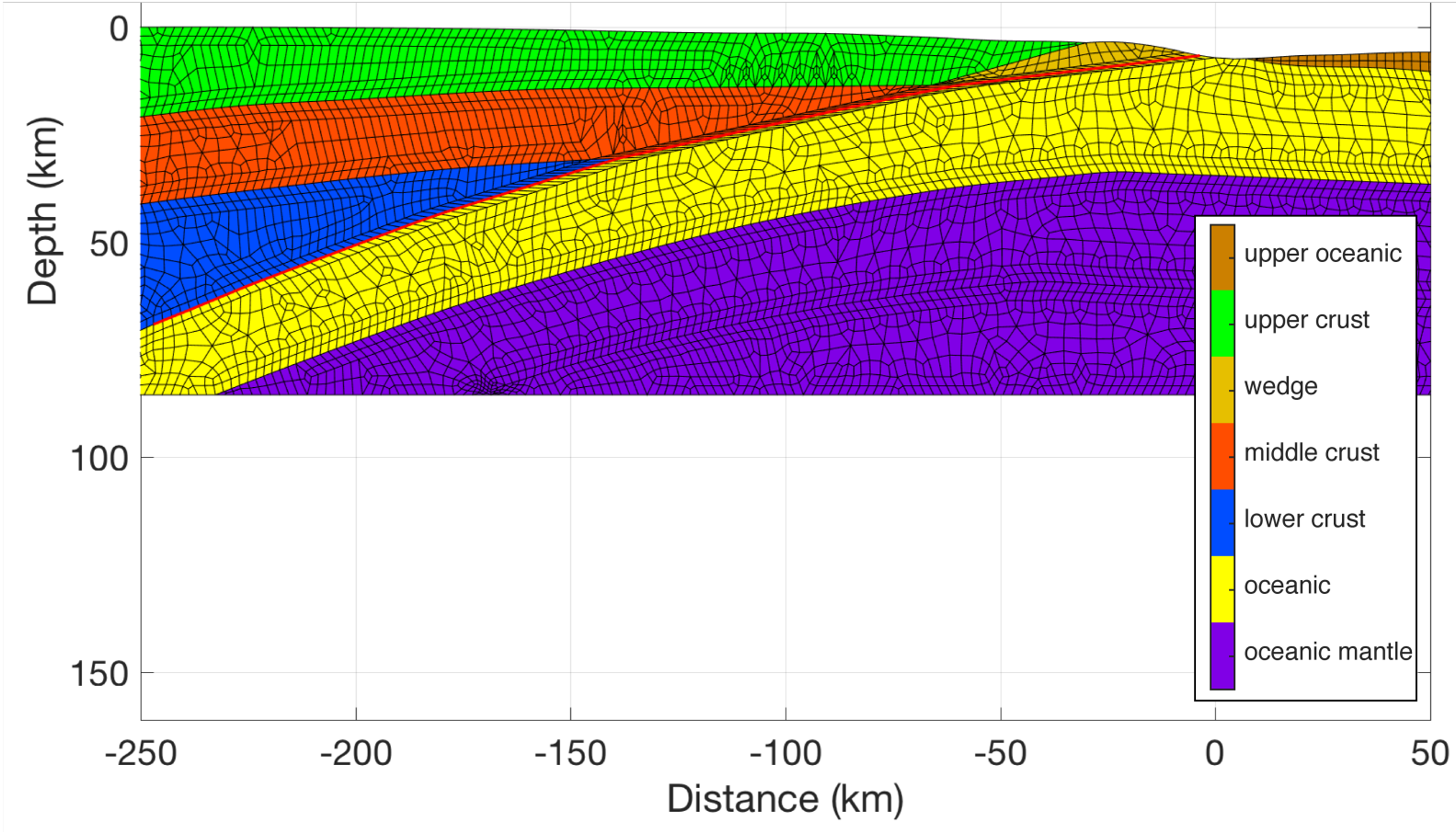

44 Figure S1: mesh used in simulations where boundary of cell is demarked by solid

45 black line. Solid red line represents the fault. Colour coding of layers is the same as 46 that used in Fig. 2 in main text. 
a)

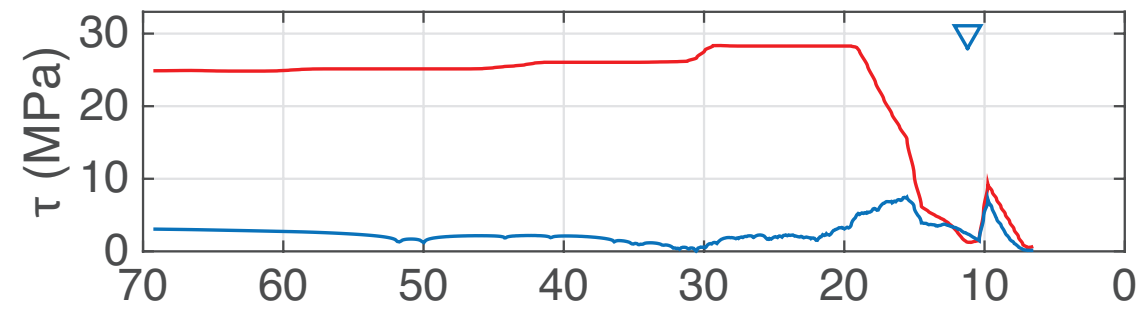

b)

Depth $(\mathrm{km})$

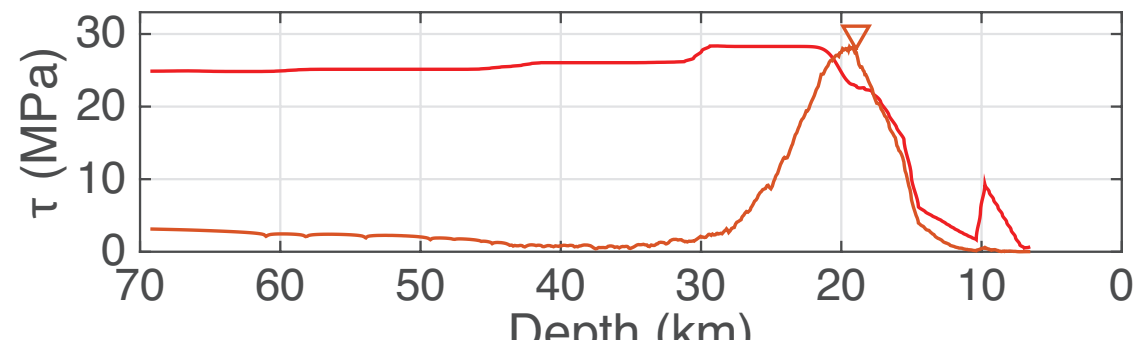

c)

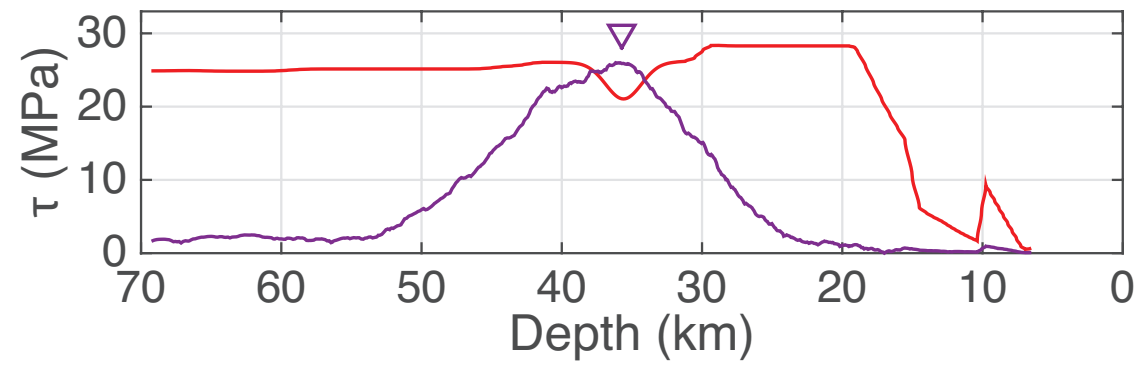

49 Figure S2: Initial stress (blue, orange, and purple lines) and yield stress (red line)

50 containing nucleation depth (denoted by triangles). a) shallow, b) intermediate and c)

51 deep case study simulations.

52 
a)
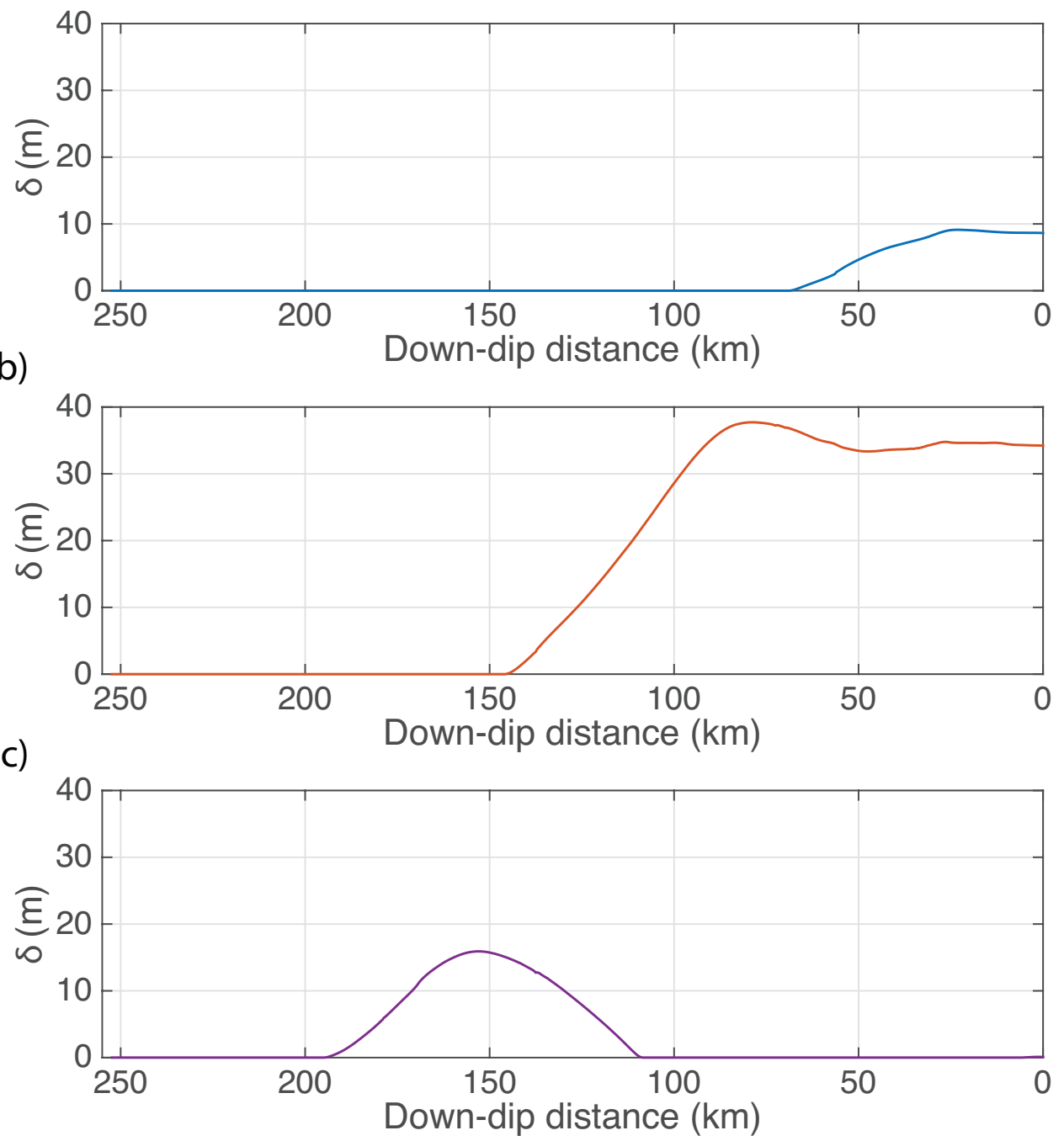

53

54 Figure S3: Final slip as a function of fault down-dip distance from the free surface

55 (i.e., seafloor). a) shallow, b) intermediate and c) deep case study simulations (main 56 text Fig. 2).

57 

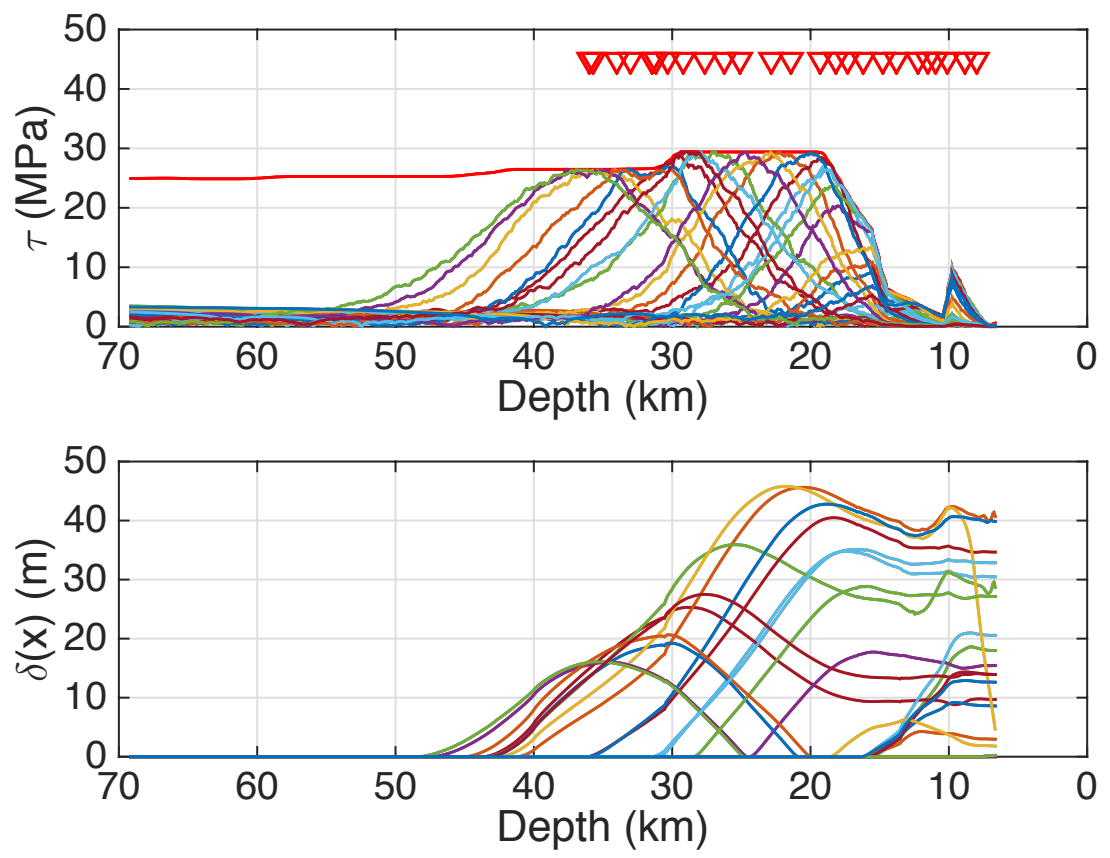

58

59 Figure S4: Initial stress (top subplot) and resulting slip distributions (bottom subplot)

60 from the simulations plotted in Fig. 3 in the main text.

61

62

63

64

65

66

67

68

69

$$
\tau=\frac{-\left(\sigma_{1}+\sigma_{2}\right)}{2} \sin 2 \theta
$$

(Eqn. S1)

70

71

$$
\sigma_{n}=\frac{\left(\sigma_{1}+\sigma_{2}\right)}{2}+\frac{\left(\sigma_{1}-\sigma_{2}\right)}{2} \cos 2 \theta
$$

72 
$74 \theta$ is the anti-clockwise rotation from the direction of maximum principal stress to the 75 normal of the fault plane which in the case of subduction zones is horizontal, the fault $76 \operatorname{dip} \phi$ is therefore defined as $\phi=\theta-\pi / 2$. Substituting Byleree's Law $\left(\tau=\mu \sigma_{n}\right.$ 77 where $\mu$ is the coefficient of friction) into Eqn S1 to replace $\tau$, this new equation can be combined with Eqn S2 to give:

$$
\sigma_{1}=\left\{\frac{\sin (2 \theta)+\mu \cos (2 \theta)-\mu}{\mu+\mu \cos (2 \theta)+\sin (2 \theta)}\right\} \sigma_{2}
$$

81

82

83

84 
101 A3. Tsunami Source

a)

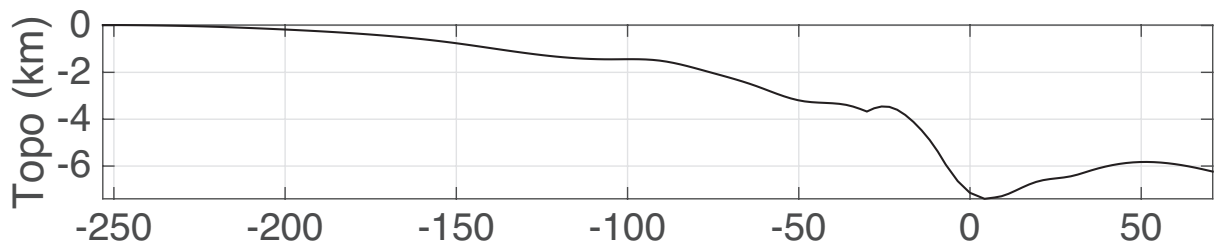

b)

Distance $(\mathrm{km})$

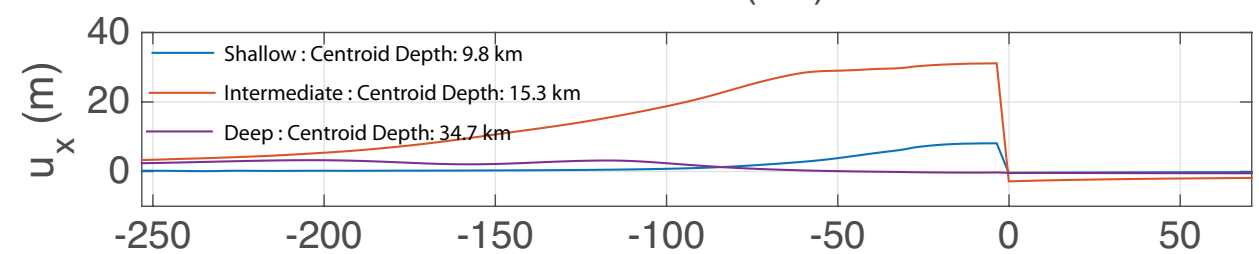

c)

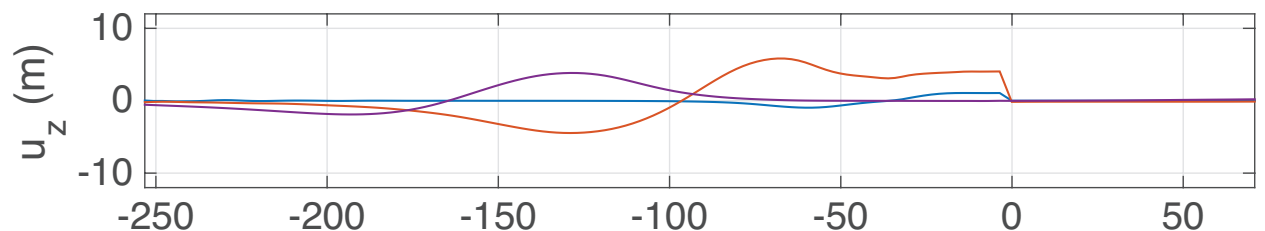

d)

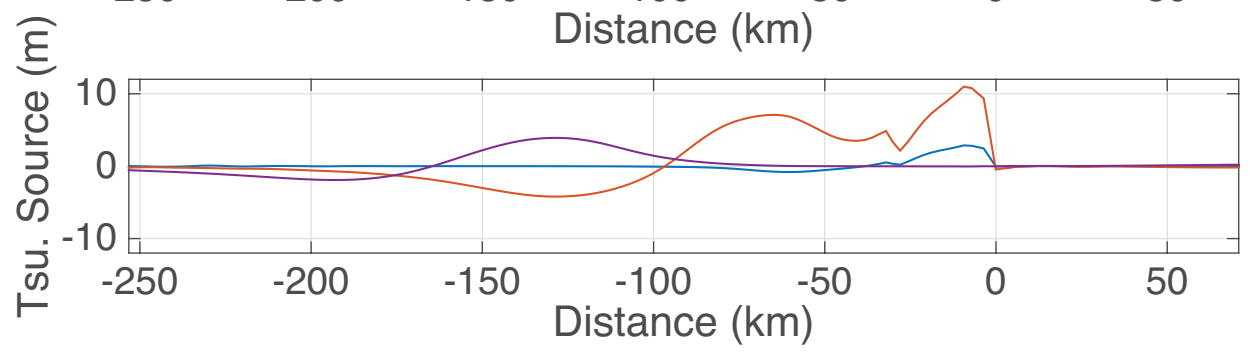

103 Figure S5: The displacement used for a tsunami source is based on the vertical 104 seafloor displacement and the horizontal motion of the trench slope. It is calculated 105 using the formula $d=u_{z}+\frac{\partial T}{\partial x} u_{x}$ where $u_{z}$ and $u_{x}$ and the vertical and horizontal 106 seafloor displacements respectively and $\frac{\partial T}{\partial x}$ is the gradient of the water depth (Tanioka 107 and Satake, 1996). a) is the seafloor depth in the numerical model, b) is the horizontal 108 displacement in the three case study simulations, c) is the vertical seafloor 109 displacement, and $\mathbf{d})$ is the displacement accounted for in a tsunami source. 
113 A4. Calculation for 1-Dimensional normalised rupture duration and seismic

114 moment

115 The normalised rupture duration is calculated in a similar manner to previous work

116 (Houston et al., 1998) however the change from a 2-D fault to a 1-D line fault needs

117 to be accounted for. In the case of this work the moment $M_{o}$ for a 1-D line is defined 118 as:

$$
M_{o}=G W \bar{\delta}
$$

122 where $G$ the shear modulus, $W$ the fault rupture width and $\bar{\delta}$ the average slip(Mitsui 123 and Yagi, 2013). The average slip can also be defined in terms of the average static 124 stress drop, $\Delta \sigma$ :

125

126

128 where $C$ is a constant and $L$ is the rupture length. Setting the $L$ equal to $W$, and 129 substituting it in terms of rupture duration (i.e., $W=T v_{r}$, where $T$ is rupture duration 130 and $v_{r}$ is rupture velocity). Combining Equations $\mathrm{S} 1, \mathrm{~S} 2$ and substituting in the 131 duration in place of the width produces:

132

133

$$
\bar{\delta}=\mathrm{C} \frac{\Delta \sigma}{G} L
$$

(Eqn. S5) 
135 This is different for the 2-D case (i.e., $T \propto M_{o}{ }^{1 / 3}$ ). Therefore, normalising the 1-D 136 duration to a given reference moment, $M_{o}^{r e f}$, is defined as:

$$
T_{N}^{1 D}=T\left(\frac{M_{o}}{M_{o}^{r e f}}\right)^{1 / 2}
$$

140 For the normalised duration for observations (Bilek and Lay, 1999) $M_{o}^{r e f}$ was set to a 141 magnitude 6 event. To make our numerical results comparable to these observations, 142 we calculated the slip distribution of a circular asperity of M 6 and calculated the 143 moment along a line through the centre of the asperity. This gave a value of $144 \quad 3.710^{14} \mathrm{~Pa} \mathrm{~m}{ }^{2}$ which $M_{o}^{r e f}$ was set equal to in Eqn. S7.

\section{A5. Sensitivity Analysis: depth at which fluid retention depth occurs}

149 Two additional ensembles were run where the fluid retention depth, $\mathrm{z}_{\mathrm{FRD}}$, was shifted $150 \pm 5 \mathrm{~km}$ of the original depth, that is depths of $7 \mathrm{~km}$ and $17 \mathrm{~km}$. The effect on yield 151 stress and initial stress distributions, is depicted in Fig. $\mathrm{S} 6$ for $\mathrm{Z}_{\mathrm{FRD}}=7 \mathrm{~km}$, and in Fig. $152 \mathrm{~S} 7$ for $\mathrm{Z}_{\mathrm{FRD}}=17 \mathrm{~km}$. In both cases 15 simulations were performed. Fig. S8 shows the 153 comparison between the three ensembles in terms of moment, average static stress 154 drop, normalised rupture duration, average breakdown energy, average slip-rate per 155 earthquake and average rupture velocity. Fig. S8 shows that the earthquakes in the 156 ensemble with $\mathrm{z}_{\mathrm{FRD}}=17 \mathrm{~km}$ are similar to case in the main text (i.e., $\mathrm{z}_{\mathrm{FRD}}=12 \mathrm{~km}$ ), 157 however the depth dependent trends are different in the case with $\mathrm{z}_{\mathrm{FRD}}=7 \mathrm{~km}$. 

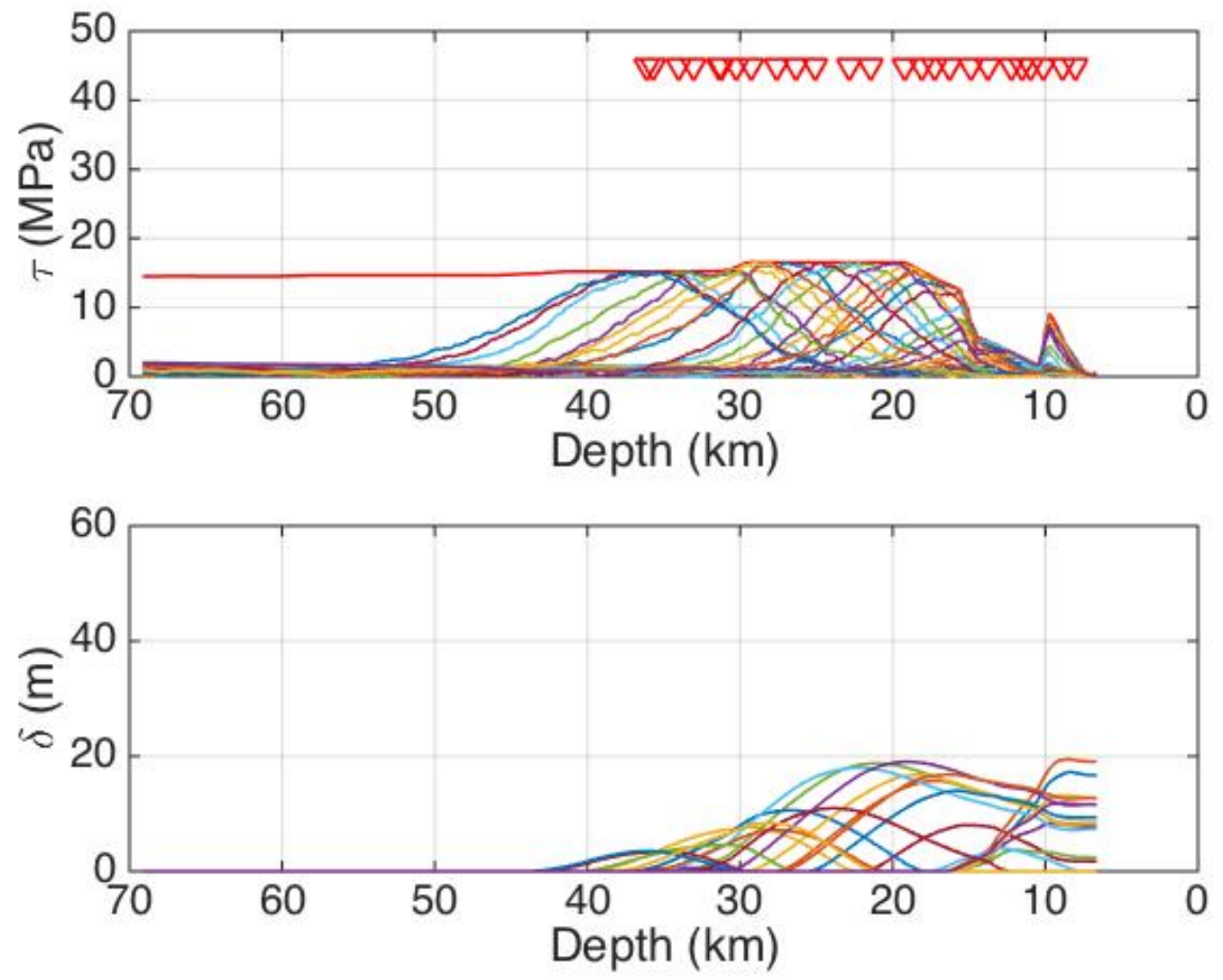

160

161 Figure S6: Initial stress (top subplot) and resulting slip distributions (bottom subplot)

162 in the $\mathrm{Z}_{\mathrm{FRD}}=7 \mathrm{~km}$ case. In the top subplot the red line is the yield stress and each

163 coloured line is an initial stress distribution used in an individual simulation. The

164 green triangles denote the location of seismic rupture nucleation. In the bottom

165 subplot the colour code of the slip distributions match colour code used for the initial

166 stress distributions used in the subplot above.

167

168

169 

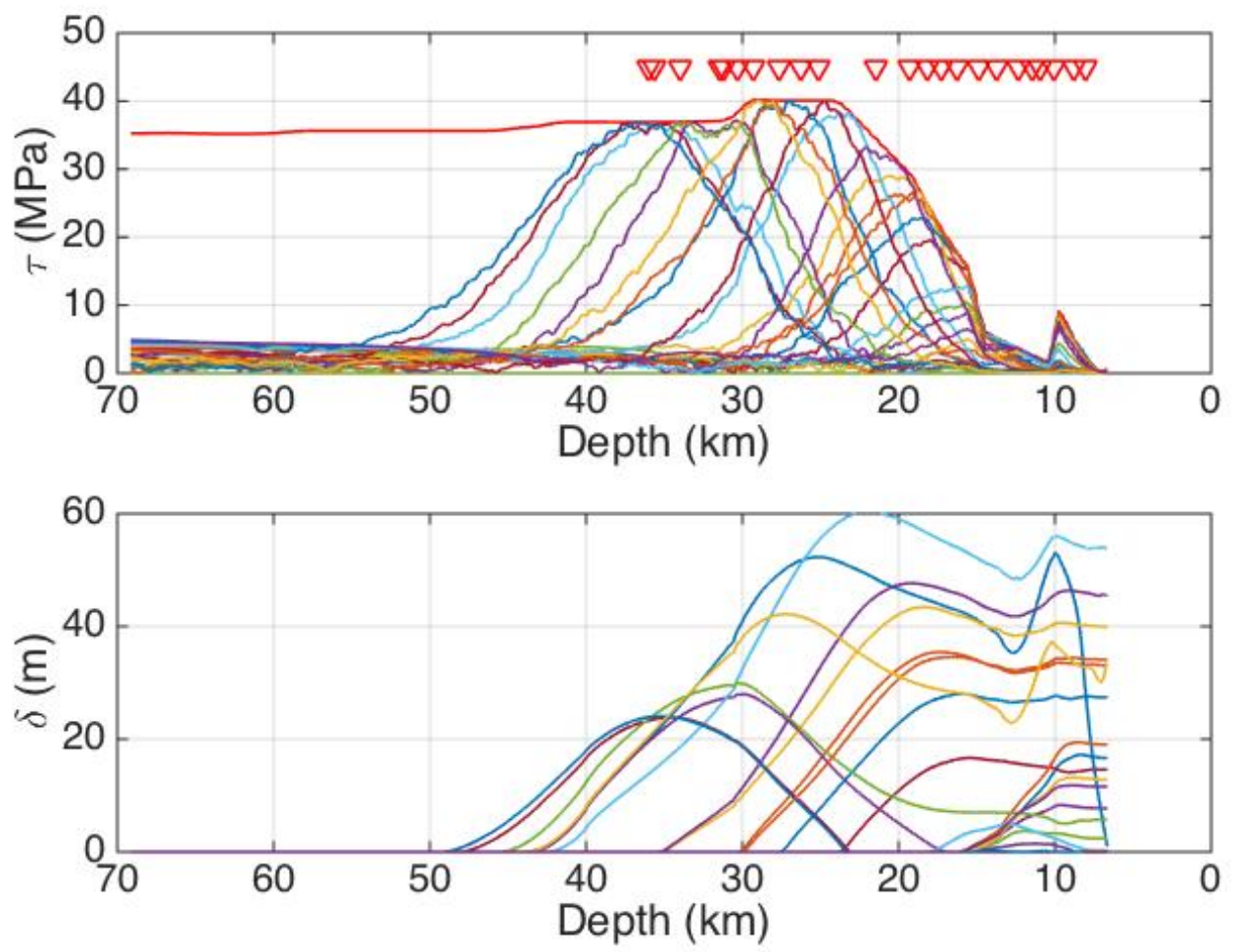

171 Figure S7: Initial stress (top subplot) and resulting slip distributions (bottom subplot)

172 in the $\mathrm{Z}_{\mathrm{FRD}}=17 \mathrm{~km}$ case. In the top subplot the red line is the yield stress and each

173 coloured line is an initial stress distribution used in an individual simulation. The

174 green triangles denote the location of the seismic rupture nucleation. In the bottom

175 subplot the colour code of the slip distributions match colour code used for the initial

176 stress distributions used in the subplot above. 
a)

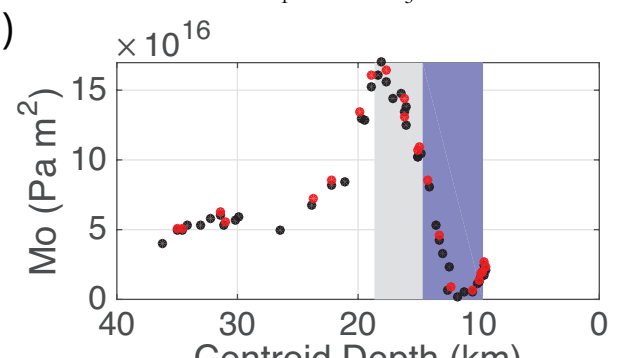

C)

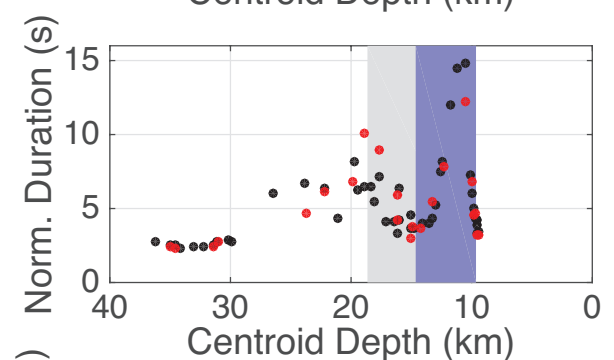

e)

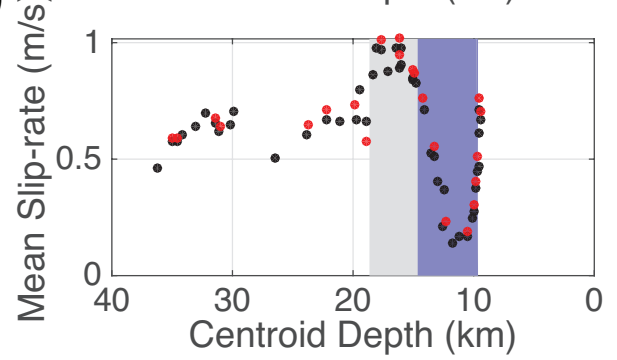

b)

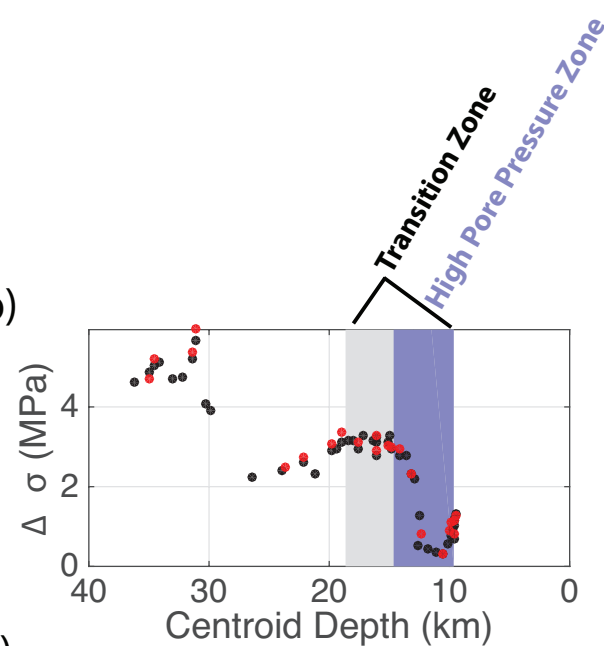

d)

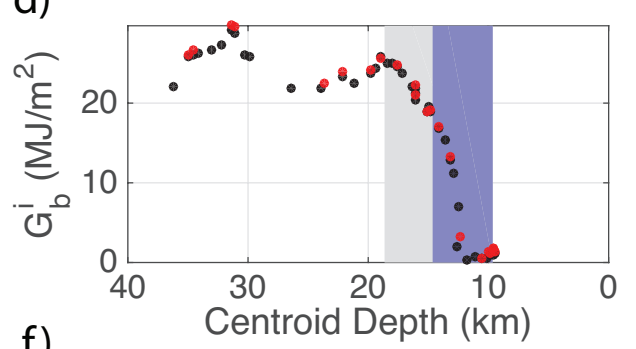

f)

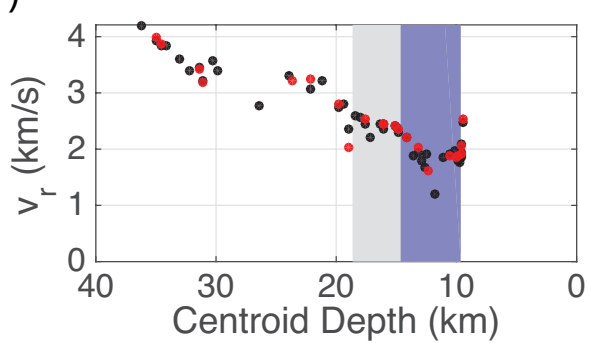

188 Figure S8: Testing the effect of changing the relationship between the principal 189 components of stress. Black dots are for the simulations as described in the main text, 190 that is $\sigma_{1}=4.05 \sigma_{3}$, while red dots are for $\sigma_{1}=5.0 \sigma_{3}$. a) Seismic moment of the 1-

191 D line earthquake; a constant $G=30 \mathrm{GPa}$ rather than a depth dependent shear 192 modulus was used in the calculation as is commonly used in observational 193 seismology. b) Average static stress drop; c) normalised rupture duration; d) average 194 breakdown energy; e) average slip-rate per earthquake and f) average rupture 195 velocity. 
A6. Averaged rupture features for 3 case studies.

\begin{tabular}{l|lll} 
& Shallow & Intermediate & Deep \\
\hline$G_{b}^{i}\left(\mathrm{MJ} / \mathrm{m}^{2}\right)$ & 1.15 & 19.6 & 25.8 \\
$\Delta \sigma(\mathrm{MPa})$ & 0.96 & 3.0 & 4.76 \\
$v_{r}(\mathrm{~km} / \mathrm{s})$ & 1.7 & 2.5 & 3.9 \\
$T_{r}(\mathrm{~s})$ & 22.6 & 31.6 & 18.6 \\
$\dot{\delta}(\mathrm{m} / \mathrm{s})$ & 0.24 & 0.65 & 0.41
\end{tabular}

197

198 Table S6: Earthquake source parameters for four simulated ruptures reported in Fig. 2

199 of the main text. Average breakdown energy $G_{b}^{i}$ based on the assumed slip weakening 200 friction law (Eq. S1), the numerical integration of stress (Eq. S2) and the average 201 static stress drop. In all cases only points where coseismic slip occurs are considered 202 when calculating the mean breakdown energy and static stress drop. $v_{r}$ is the average 203 rupture velocity, $T_{r}$ is the average rise time and $\dot{\delta}$ is the average slip-rate on the fault. 204 All averaged values are based on section of the fault that slips.

205

206

207

208

209

210

211

212

213

214

215 


\section{References}

Bilek, S.L., Lay, T., 1999. Rigidity variations with depth along interplate megathrust faults in subduction zones. Nature 400, 443-446. doi:10.1038/22739

Brace, W.F., Kohlstedt, D.L., 1980. Limits on lithospheric stress imposed by laboratory experiments. Journal of Geophysical Research: Solid Earth (19782012) 85, 6248-6252. doi:10.1029/JB085iB11p06248

Brantut, N., Schubnel, A., Rouzaud, J.N., Brunet, F., Shimamoto, T., 2008. Highvelocity frictional properties of a clay-bearing fault gouge and implications for earthquake mechanics. Journal of Geophysical Research: Solid Earth (19782012) 113, B10401. doi:10.1029/2007JB005551

Bullock, R.J., De Paola, N., Holdsworth, R.E., 2015. An experimental investigation into the role of phyllosilicate content on earthquake propagation during seismic slip in carbonate faults. J Geophys Res-Sol Ea 120, 3187-3207. doi:10.1002/2015JB011914

Del Gaudio, P., Di Toro, G., Han, R., Hirose, T., Nielsen, S., Shimamoto, T., Cavallo, A., 2009. Frictional melting of peridotite and seismic slip. Journal of Geophysical Research 114, B06306-19. doi:10.1029/2008JB005990

Ferri, F., Di Toro, G., Hirose, T., Han, R., Noda, H., Shimamoto, T., Quaresimin, M., de Rossi, N., 2011. Low- to high-velocity frictional properties of the clay-rich gouges from the slipping zone of the 1963 Vaiont slide, northern Italy. Journal of Geophysical Research: Solid Earth (1978-2012) 116, B09208. doi:10.1029/2011JB008338

Hirono, T., Tsuda, K., Tanikawa, W., Ampuero, J.-P., Shibazaki, B., Kinoshita, M., Mori, J.J., 2016. Near-trench slip potential of megaquakes evaluated from fault properties and conditions. Sci. Rep. 1-13. doi:10.1038/srep28184

Houston, H., Benz, H.M., Vidale, J.E., 1998. Time functions of deep earthquakes from broadband and short-period stacks. J Geophys Res-Sol Ea 103, 2989529913. doi:10.1038/ncomms3606

Jaeger, J.C., Cook, N., Zimmerman, R., 2007. Fundamentals of rock mechanics.

Ma, S., 2012. A self-consistent mechanism for slow dynamic deformation and tsunami generation for earthquakes in the shallow subduction zone. Geophys. Res. Lett 39, n/a-n/a. doi:10.1029/2012GL051854

Mitsui, Y., Yagi, Y., 2013. An interpretation of tsunami earthquake based on a simple dynamic model: Failure of shallow megathrust earthquake. Geophys. Res. Lett 40, 1523-1527. doi:10.1002/grl.50266

Mizoguchi, K., Hirose, T., Shimamoto, T., Fukuyama, E., 2009. High-velocity frictional behavior and microstructure evolution of fault gouge obtained from Nojima fault, southwest Japan. Tectonophysics 471, 285-296. doi:10.1016/j.tecto.2009.02.033

Proctor, B.P., Mitchell, T.M., Hirth, G., Goldsby, D., Zorzi, F., Platt, J.D., Di Toro, G., 2014. Dynamic weakening of serpentinite gouges and bare surfaces at seismic slip rates. J Geophys Res-Sol Ea 119, 8107-8131. doi:10.1002/2014JB011057

Tanioka, Y., Satake, K., 1996. Tsunami generation by horizontal displacement of ocean bottom. Geophys. Res. Lett 23, 861-864. doi:10.1029/96GL00736

Togo, T., Shimamoto, T., Ma, S., Hirose, T., 2011. High-velocity frictional behavior of Longmenshan fault gouge from Hongkou outcrop and its implications for dynamic weakening of fault during the 2008 Wenchuan earthquake. Earthq Sci 
24, 267-281. doi:10.1007/s11589-011-0790-6

Yao, L., Ma, S., Shimamoto, T., Togo, T., 2013a. Structures and high-velocity frictional properties of the Pingxi fault zone in the Longmenshan fault system, Sichuan, China, activated during the 2008 Wenchuan earthquake. Tectonophysics 599, 135-156. doi:10.1016/j.tecto.2013.04.011

Yao, L., Shimamoto, T., Ma, S., Han, R., Mizoguchi, K., 2013b. Rapid postseismic strength recovery of Pingxi fault gouge from the Longmenshan fault system: Experiments and implications for the mechanisms of high-velocity weakening of faults. J Geophys Res-Sol Ea 118, 4547-4563. doi:10.1002/jgrb.50308 